\title{
A systematic review to identify biomarkers of intake for fermented food products
}

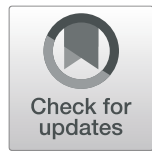

\author{
Katherine J. Li ${ }^{1,2^{*}}$ (D), Elske M. Brouwer-Brolsma', Kathryn J. Burton-Pimentel ${ }^{2}$, Guy Vergères ${ }^{2}$ and \\ Edith J. M. Feskens ${ }^{1}$
}

\begin{abstract}
Background: Fermented foods are ubiquitous in human diets and often lauded for their sensory, nutritious, and health-promoting qualities. However, precise associations between the intake of fermented foods and health have not been well-established. This is in part due to the limitations of current dietary assessment tools that rely on subjective reporting, making them prone to memory-related errors and reporting bias. The identification of food intake biomarkers (FIBs) bypasses this challenge by providing an objective measure of intake. Despite numerous studies reporting on FIBs for various types of fermented foods and drinks, unique biomarkers associated with the fermentation process ("fermentation-dependent" biomarkers) have not been well documented. We therefore conducted a comprehensive, systematic review of the literature to identify biomarkers of fermented foods commonly consumed in diets across the world.

Results: After title, abstract, and full-text screening, extraction of data from 301 articles resulted in an extensive list of compounds that were detected in human biofluids following the consumption of various fermented foods, with the majority of articles focusing on coffee (69), wine (69 articles), cocoa (62), beer (34), and bread (29). The identified compounds from all included papers were consolidated and sorted into FIBs proposed for a specific food, for a food group, or for the fermentation process. Alongside food-specific markers (e.g., trigonelline for coffee), and foodgroup markers (e.g., pentadecanoic acid for dairy intake), several fermentation-dependent markers were revealed. These comprised compounds related to the fermentation process of a particular food, such as mannitol (wine), 2ethylmalate (beer), methionine (sourdough bread, cheese), theabrownins (tea), and gallic acid (tea, wine), while others were indicative of more general fermentation processes (e.g., ethanol from alcoholic fermentation, 3phenyllactic acid from lactic fermentation).

Conclusions: Fermented foods comprise a heterogeneous group of foods. While many of the candidate FIBs identified were found to be non-specific, greater specificity may be observed when considering a combination of compounds identified for individual fermented foods, food groups, and from fermentation processes. Future studies that focus on how fermentation impacts the composition and nutritional quality of food substrates could help to identify novel biomarkers of fermented food intake.
\end{abstract}

Keywords: Fermented foods, Dietary biomarkers, Metabolites, Dietary assessment, Food intake biomarkers

\footnotetext{
* Correspondence: katherine.li@wur.nl

${ }^{1}$ Division of Human Nutrition and Health, Department of Agrotechnology and Food Science, Wageningen University \& Research, Wageningen,

Netherlands

${ }^{2}$ Food Microbial Systems Research Division, Federal Department of Economic Affairs, Education and Research (EAER), Federal Office for Agriculture (FOAG), Agroscope, Bern, Switzerland
}

(c) The Author(s). 2021 Open Access This article is licensed under a Creative Commons Attribution 4.0 International License, which permits use, sharing, adaptation, distribution and reproduction in any medium or format, as long as you give appropriate credit to the original author(s) and the source, provide a link to the Creative Commons licence, and indicate if changes were made. The images or other third party material in this article are included in the article's Creative Commons licence, unless indicated otherwise in a credit line to the material. If material is not included in the article's Creative Commons licence and your intended use is not permitted by statutory regulation or exceeds the permitted use, you will need to obtain permission directly from the copyright holder. To view a copy of this licence, visit http://creativecommons.org/licenses/by/4.0/. 


\section{Background}

Fermentation as a food processing technology has been used for millennia to enhance the flavor, texture, and nutritive value of foods, as well as to improve their transportability, storage time, and/or safety [1, 2]. Fermentation techniques continue to be refined and applied to a wide range of foods, including milk, grains, legumes, fruits, vegetables, fish, and meat products. Common types of fermented foods vary by region; for example, fermented dairy products (e.g., cheese, yoghurt, buttermilk) are produced and consumed abundantly in Europe, fermented pulses and cereals (e.g., dosai, idli, injera) are mostly indigenous to South Asia and Africa, and fermented soy products (e.g., natto, miso, soy sauce, doubanjiang) are particularly common in East Asia [3-5]. Other products are less regionally or culturally dependent, such as fermented fish products that are consumed in Korea (sikhae) and Japan (narezushi), as well as Sweden (surströmming) and Norway (rakfisk) [4, 6]. The endless combination of foods (or "substrates"), microorganisms, and fermentation techniques results in global fermented products with vastly different sensory and nutritional profiles. Currently, over 5000 types of fermented foods and beverages exist worldwide [7], and continued growth of the fermented food market is anticipated and fuelled by health food trends and rejuvenated artisanal practices.

Fermented foods are produced by the controlled growth and enzymatic activities of microorganisms, through four main fermentation processes (lactic, acetic, alcoholic, and alkaline) [4, 8]. Lactic fermentations are carried out by lactic acid bacteria (LAB) (predominantly Lactobacillus, Streptococcus, Pediococcus, and Leuconostoc) for the production of fermented dairy, meat, and vegetable products, whereas acetic acid bacteria (e.g., Gluconacetobacter) are responsible for the fermentation of cocoa, vinegar, and kombucha $[9,10]$. Alcoholic fermentations are driven by yeasts (e.g., Saccharomyces cerevisiae) for the production of beer, wine, and breads, while alkaline fermentations make use of fungi (e.g., Penicillium spp. and Aspergillus spp.) during the production and maturation of cheese, fermented meats, and fermented soy products $[11,12]$. Irrespective of the type of fermentation, microbial enzymes interact with the food matrix to produce novel metabolites, which can affect the sensory and functional profile of foods [13-20]. and have also been suggested to possess bioactive qualities that can help prevent chronic diseases such as diabetes and cardiovascular disease [17].

Fundamental research suggests that the protective effects of fermented foods may be explained by fermentation-induced increases in the bioavailability of certain macro- and micronutrients (e.g., protein, vitamins) [21], fermentation-induced decreases in anti- nutritional compounds [22], or driven by novel bioactive compounds of microbial metabolism [7]. While several human observational studies have indicated a possible beneficial association between fermented food consumption and cardiometabolic health, specifically in terms of weight maintenance, diabetes/glucose homeostasis, and overall cardiovascular disease risk [23-25], the evidence is still inconclusive, in part due to the limitations of tools used to quantify fermented food intake.

Currently, self-report food frequency questionnaires (FFQs), 24-h recalls, and food diaries (weighed or unweighed) are the most commonly used dietary assessment tools to quantify food intake. The FFQ is usually the method of choice in observational cohort studies. In contrast to diaries and recalls, FFQs are relatively easy to administer and process, but their accuracy relies on the memory and devotion of respondents. Consequently, random and systematic errors, including memoryrelated bias, incorrect estimates of portion sizes, and/or bias towards socially desirable answers, are inevitable $[26,27]$. There is also no FFQ that has been specifically designed to estimate fermented food intake, and food lists in existing FFQs may not comprehensively cover the intakes of this diverse food group, or distinguish the nuances within specific foods that affect their fermentation status (e.g., fermented pickles vs. acidified pickles). Moreover, none of the self-report dietary assessment methods takes into account differences in food metabolism between individuals, which can have a significant bearing on the immediate effects of diet and subsequent health consequences. The importance of accurately assessing food intake across diverse populations has propelled food intake biomarkers (FIBs), as promising "objective" measures of intake and metabolism, to the forefront of dietary assessment research $[26,28]$.

While the identification of a single specific biomarker is ideal, this is not always possible due to the overlapping characteristics shared by many foods. A number of combination biomarkers have thus been proposed, for example in the case of red wine (tartaric acid reflecting the grape raw material, plus ethyl glucuronide reflecting alcoholic fermentation and phase II metabolism) [29]. A similar approach is expected to be suitable for identifying FIBs for other fermented food products, such that a group of compounds, although not unique to the food themselves, might be useful in combination to stratify between high and low consumers of different fermented foods in intervention studies and epidemiological cohorts.

The Food Biomarker Alliance (FoodBAll) [28], a project funded by the Joint Programming Initiative a Healthy Diet for a Healthy Life, has set guidelines for identifying and validating FIBs [30] (http:// foodmetabolome.org) [31]. This effort has resulted in a 
systematic documentation of FIBs for major food groups, including fruit and vegetables, meats, fish, and other seafood, dairy products, cereals and whole grains, alcoholic and non-alcoholic beverages, vegetable oils, nuts, and spices and herbs [32-40]. The purpose of the current systematic review is to present a comprehensive overview of compounds reported in the literature that could, alone or in combination, represent FIBs for various fermented foods. We anticipated that identified compounds could be stratified into FIBs at the food level, food group level, and fermentation level, to discriminate a dietary pattern of fermented food consumption.

\section{Methods}

\section{Primary database search}

The literature search strategy and search terms were developed in accordance with the guidelines previously proposed by the FoodBAll consortium [30], and all elements of the PRISMA (Preferred Reporting Items for Systematic reviews and Meta-Analyses) statement relevant for a literature search on biomarkers were reported [41]. Primary articles were identified from PubMed, Scopus, and ISI Web of Knowledge. In order to obtain a broad coverage of fermented food products consumed globally, eight food groups were defined for the search strategy, specifically: (i) general fermented foods, (ii) fermented dairy, (iii) fermented meats and fish, (iv) fermented fruits and vegetables, (v) fermented legumes (including soy), (vi) fermented cereals and grains, (vii) fermented beverages, and (viii) other fermented products (e.g., chocolate, condiments, and sauces). These food groups were loosely based on the food-based dietary guidelines in The Netherlands, Switzerland, and the USA [42-44], but were inclusive of fermented food items consumed worldwide. Individual fermented foods were further specified within each food group, as detailed in Additional File 1. Exclusion terms were individually applied to each search to limit the number of false-positive hits. Each of the eight food group terms was searched for in conjunction with a combination of search operators, as detailed in Additional File 2. The search fields applied were [Title/Abstract] for PudMed, [Title/Abstract/Keywords] for Scopus, and [Topic] for ISI Web of Knowledge. All searches were conducted in October 2018, and an updated literature search was performed in September 2020. No restrictions were applied on the publication date. Furthermore, the reference lists of relevant systematic reviews and meta-analyses [3234] were scanned for relevant articles for inclusion. The full literature search process is outlined in Fig. 1.

\section{Inclusion and exclusion criteria}

Search inclusion and exclusion criteria were defined a priori. Studies were included if the primary exposure was oral consumption of a fermented food, where "fermented food" was defined according to the definition given by Marco et al.: "foods or beverages made through controlled microbial growth and enzymatic conversions of major and minor food components" [8]. The study had to be conducted in humans and report on compounds that could be detected in biosamples following consumption of a fermented food. Studies were excluded if the food being considered was not fermented or if it was unclear if the food was fermented; the route of exposure to the food was not oral consumption; the amount of food consumed was not well-documented (e.g., a gram amount, or categorization to distinguish the fermented food from other foods consumed was not provided); the study was conducted in animals or in vitro; compounds in biological samples that could represent food biomarkers were not described; the aim of the study was either to review nutrient bioactivity and nutritional status using the fermented food as a delivery matrix or to assess the impact of a fermented food on the bioavailability of another food/compound; the study focused on a compound, supplement, or extract rather than a whole food; or the study only investigated alterations on the composition of the gut or fecal microbiota. Review articles, case reports or short communications (e.g., comment, editorial, conference abstract), and articles in a language other than English were also excluded.

\section{Strategy to identify and select the most discriminant compounds}

Since our goal in this review was to evaluate a combination of candidate biomarkers for fermented foods (both specific and non-specific), rather than a single specific biomarker, we slightly deviated from the assessment of validity for putative/candidate biomarkers that was previously proposed by Dragsted et al. [31]. Following the selection of relevant full-text articles for inclusion, a series of steps were applied to select the most discriminant candidate biomarkers from the literature search. These included compounds that were highly discriminant for (i) the food ("food-level" biomarkers - i.e., FIBs specific for the intake of a particular food), (ii) food group ("food group-level" biomarkers - i.e., FIBs specific for the intake of a group of foods with a common raw material substrate or characteristic), or (iii) a dietary pattern of fermented food consumption ("fermentationdependent" biomarkers - i.e., FIBs arising from the fermentation process of a food), from other non-fermented foods and food groups. In order to capture both specific markers that can discriminate the intake of a fermented food as well as non-specific markers that may act in combination to discriminate the intake of a fermented food, we firstly focused on summarizing in detail the compounds that were identified in discovery-driven 


\begin{tabular}{|c|}
\hline $\begin{array}{c}\text { General Fermented Foods } \\
\text { Pubmed }(n=1,630) \\
\text { Scopus }(n=827) \\
\text { Web of Science }(n=696)\end{array}$ \\
\hline $\begin{array}{c}\text { Fermented Legumes/Soy } \\
\text { Pubmed }(n=82) \\
\text { Scopus }(n=54) \\
\text { Web of Science }(n=40)\end{array}$ \\
\hline
\end{tabular}

Fermented Meat \& Fish

Pubmed $(n=132)$

Scopus $(n=100)$

Web of Science $(n=56)$

Fermented Beverages

Pubmed $(n=2,245)$

Scopus $(n=1,232)$

Web of Science $(n=1,071)$

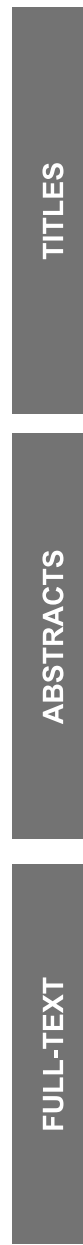

7,686 Unique Entries

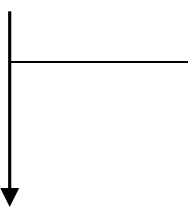

2,796 Included

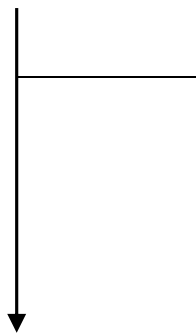

473 Included

\section{Excluded}

271 Included
Fermented Dairy

Pubmed $(n=716)$

Scopus $(n=294)$

Web of Science $(n=233)$

Fermented Cereals \& Grains

Pubmed $(n=329)$

Scopus $(n=347)$

Web of Science $(n=249)$

\begin{tabular}{|l|}
\hline Fermented Fruits \& Vegetables \\
Pubmed $(n=151)$ \\
Scopus $(n=70)$ \\
Web of Science $(n=52)$
\end{tabular}

Other Fermented Foods

Pubmed $(n=554)$

Scopus $(n=312)$

Web of Science $(n=292)$

Duplicate entries excluded $(n=4,078)$

4,890 Excluded

Not a fermented food $(n=4,143)$

Not orally consumed $(n=4)$

Animal or in vitro study $(n=324)$

Not a dietary biomarker study $(n=83)$

Nutrient bioactivity/efficacy biomarkers $(n=6)$

Review article $(n=4)$

Case report or short communication $(n=22)$

Article not in English and title not relevant $(n=70)$

A compound, supplement, or extract $(n=234)$

\section{2,323 Excluded}

Not a fermented food $(n=178)$

Not orally consumed $(n=2)$

Animal or in vitro study $(n=209)$

Not a dietary biomarker study $(n=1,403)$

Nutrient bioactivity/efficacy biomarkers $(n=41)$

Review article $(n=278)$

Case report or short communication $(n=10)$

Article not in English and title not relevant $(n=1)$

A compound, supplement, or extract $(n=75)$

Effect on gut microbiota only $(n=65)$

Effects on nutritional status $(n=62)$

Not a fermented food $(n=27)$

Amount not well-documented $(n=14)$

Animal or in vitro study $(n=13)$

Not a dietary biomarker study $(n=60)$

Nutrient bioactivity/efficacy biomarkers $(n=23)$

Review article $(n=17)$

Case report or short communication $(n=8)$

A compound, supplement, or extract $(n=18)$

Effect on gut microbiota only $(n=10)$

Effects on nutritional status $(n=5)$

Not retrievable $(n=7)$

Updated literature search $(n=30)$

\section{Total Relevant Articles Included}

Fig. 1 Schematic outline of the systematic literature search 
"untargeted" studies that typically employed metabolomics tools (58 articles), and supplemented this information with "targeted" studies investigating a particular compound or set of compounds (243 articles), analyzed using metabolomics tools or other biochemical assays. Information from the untargeted studies was expected to identify biomarkers associated with a dietary pattern of consuming fermented foods, while information from both the untargeted and targeted studies was expected to help to further identify and verify biomarkers at the food level (e.g., cheese) and food group level (e.g., fermented dairy).

Compounds were selected if they were statistically significantly increased following consumption of the fermented food compared to baseline or control, and/or have been detected in multiple studies. For these selected compounds, we further consulted the study text to assess the biological plausibility, along with previous FIB reviews for their validation status. In addition, three food/metabolite databases (HMDB, Exposome-Explorer, FooDB) were searched in May 2019 and updated in September 2020 as an additional step for verifying that a compound appearing in a biosample has a food origin (or was transformed during metabolism) and to check the specificity of the compound for a fermented food. Information from food databases and the wider literature were also used to identify and confirm metabolites of fermentation. Compounds that were not discriminative of these classifiers but were associated with the fermented food or food group (e.g., detected but not significantly increased in biosamples following consumption), or compounds which have a ubiquitous presence across many other non-fermented foods, were not selected and not further discussed.

\section{Results and discussion Database search}

From the initial primary database search, a total of 11 , 764 records were identified, of which 7686 unique entries remained following the removal of duplicates (Fig. 1). After filtering the 7686 titles, 4890 were excluded and 2794 were deemed relevant for further review and their abstracts were retrieved. Following abstract review, 473 relevant entries remained, and their full-text articles were retrieved (2323 were excluded for various reasons outlined in the exclusion criteria). Further application of exclusion criteria to full-text articles (202 articles removed), and an updated search (30 articles added), resolved in 301 relevant full-text articles with information on compounds associated with intake of various fermented foods. The fermented foods investigated in the $n=$ 301 studies were coffee $(n=69)$, wine $(n=69)$, cocoa $(n$ $=62)$, beer $(n=34)$, bread $(n=29)$, fermented soy $(n=$ $22)$, cheese $(n=18)$, yoghurt $(n=15)$, fermented milk ( $n$
$=3)$, post-fermented tea $(n=3)$, vinegar $(n=2)$, cider $(n$ $=1$ ), traditional Turkish beverages (salgam, boza, kefir, and kimiz) $(n=1)$, fermented orange juice $(n=1)$, fermented ginseng $(n=1)$, fermented beet juice $(n=1)$, fermented red cabbage $(n=1)$, soy sauce $(n=1)$, sauerkraut $(n=1)$, and general fermented products $(n=1)$ (Fig. 2a). The numbers of identified metabolites reported for each food across these studies are presented in Fig. $2 \mathrm{~b}$, and detailed lists of all of the included articles are presented in Additional File 3 (untargeted studies) and Additional File 4 (targeted studies). No studies reported on potential FIBs for fermented meat or fish products. Biological samples in which putative FIBs were identified or measured included serum (14 untargeted, 28 targeted studies), plasma (15 untargeted, 120 targeted studies), whole blood (13 targeted studies), urine (33 untargeted, 125 targeted studies), feces (5 untargeted, 7 targeted studies), ileal fluid (5 targeted studies), subcutaneous adipose tissue ( 2 targeted studies), oral fluid (3 targeted studies), plasma lipoproteins (2 targeted studies), erythrocytes (2 untargeted studies), capillary blood (1 targeted study), breast milk (1 targeted study), hair (1 targeted study), and breath (1 targeted study). The majority of studies were postprandial intervention studies $(n=183)$. The remainder comprised short-term and long-term intervention studies $(n=83)$ and observational studies where participants followed their habitual diet (where the diet was assessed by self-report tools such as FFQ, recall, food record, or dietary history) $(n=53)$.

From these relevant publications, compounds that could represent FIBs for various fermented foods are discussed based on their classification into three categories: food-level, food group-level, and fermentationdependent FIBs (as described in the "Methods" section). An overview of the main FIBs identified, selected, and classified in this search is provided in Table 1. Although the aim of this review was not to identify a complete list of food-level or food group-level biomarkers, their inclusion in this review alongside fermentation-dependent markers provides the basis to help to facilitate a socalled multi-marker approach in estimating fermented food intake. Such a multi-marker approach could help confirm fermented food intake, or help distinguish between the intake of fermented and non-fermented versions of the same food.

\section{Food-level biomarkers}

Due to the overlapping compositional profiles of many foods, identification of specific FIBs for individual foods is challenging. In this review, food-level biomarkers were identified for beer, bread, wine, coffee, cheese, and fermented (rooibos) tea (Table 1). These compounds were largely derived from the (unfermented) raw materials. For example, isoxanthohumol, 8-prenylnaringenin, and iso- 


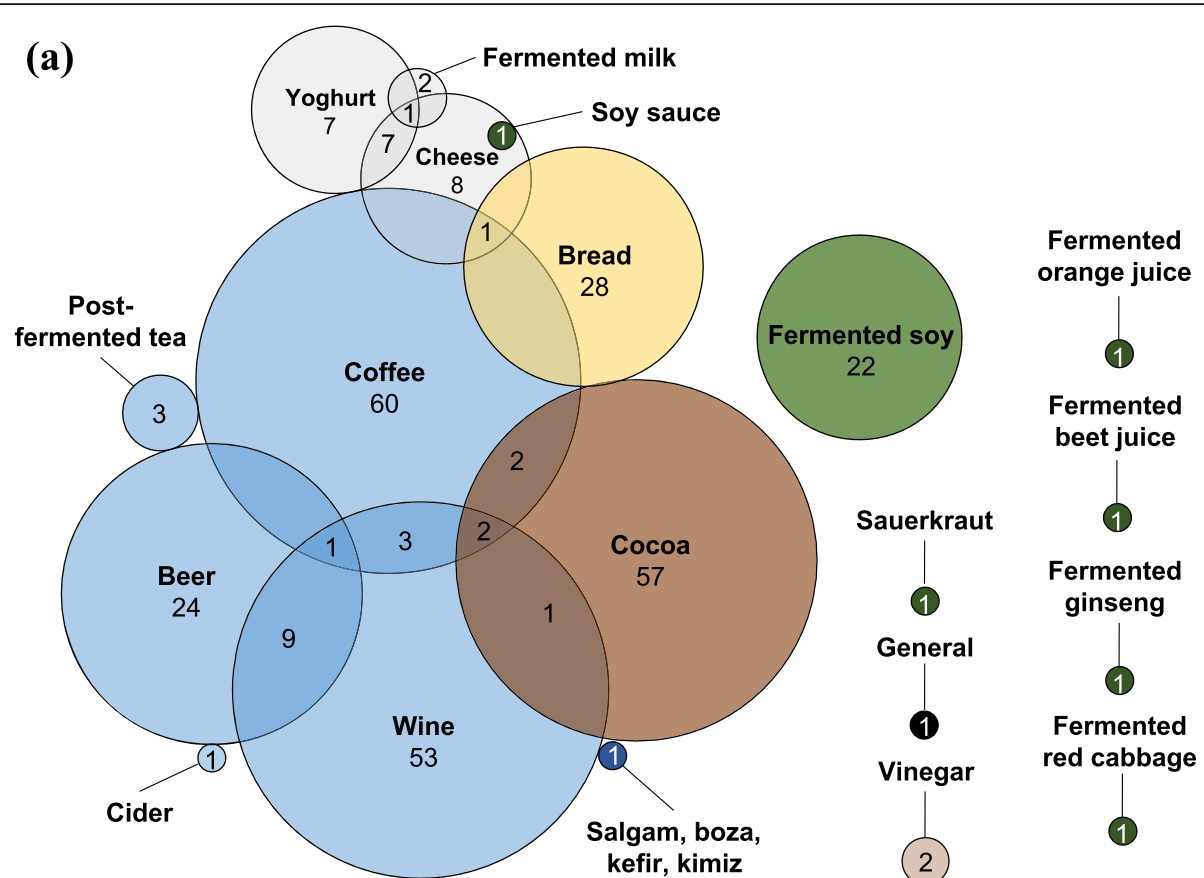

(b)

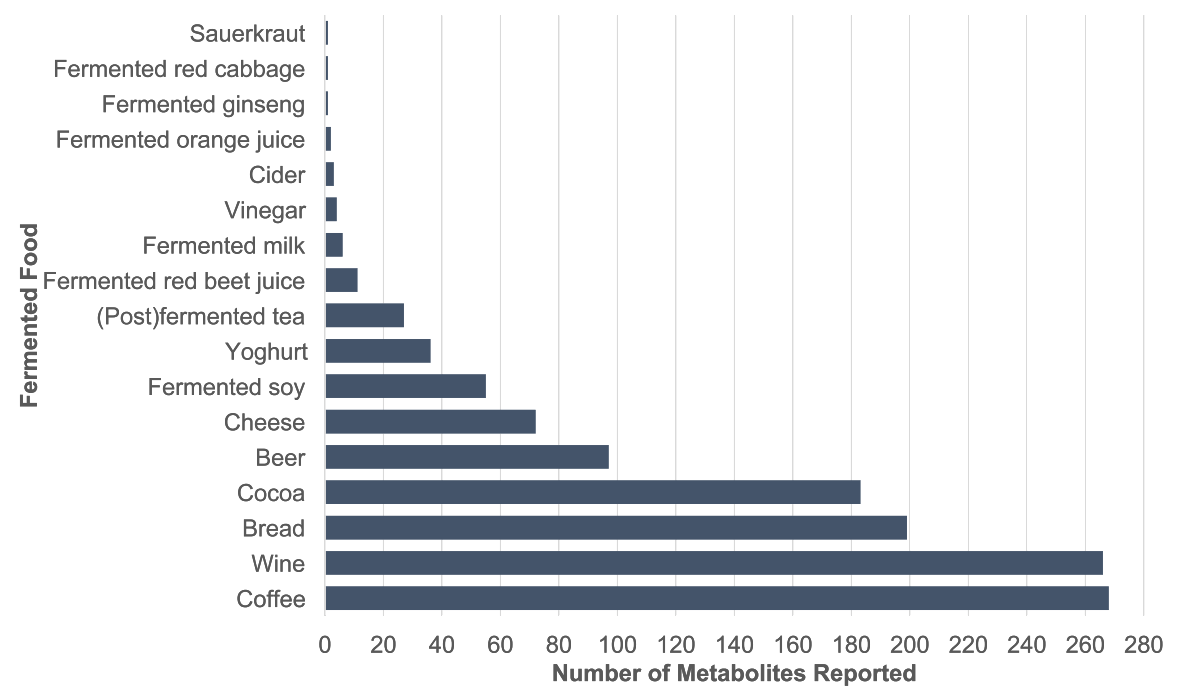

Fig. 2 Overview of 301 included publications from the systematic literature search. a Number of publications identified for each type of fermented food (colored by food group). No articles were identified for fermented meat or fish products. $\mathbf{b}$ Number of identified metabolites reported in the included articles for the fermented food described

alpha-acids originate from beer hops that are used in the brewing process; tartaric acid and resveratrol are found at high concentrations in the grapes used for wine production [45-48]; and trigonelline and 2-furoylglycine originate from coffee beans and the coffee roasting process [49, 50]. For bread, the organic acids 2,4-dihydroxybutanoic acid and 2,8-dihydroxyquinoline glucuronide were identified following the intake of fermented sourdough endosperm rye and white wheat bread
[51]. While these organic acids have seemingly not yet been detected/quantified in other foods (from food database searches), future validation would be useful in determining their usefulness as specific biomarkers for bread intake.

Food-specific biomarkers for fermented dairy products (cheese, yoghurt, buttermilk) [34], coffee [33], and cocoa products $[32,52]$ have also been the subject of previous systematic reviews. Notably, isovalerylglutamic acid, 
Table 1 Candidate FIBs identified for various fermented foods from the systematic literature search

\begin{tabular}{|c|c|c|c|c|c|}
\hline \multirow{3}{*}{$\begin{array}{l}\begin{array}{l}\text { Fermented } \\
\text { food(s) }\end{array} \\
\text { Wine }\end{array}$} & \multicolumn{5}{|c|}{ Discriminant compounds/candidate biomarker level ${ }^{a}$} \\
\hline & \multirow{2}{*}{$\begin{array}{l}\text { Food-level } \\
\text { - Tartaric acid/tartrate } \\
\text { - Resveratrol and } \\
\text { metabolites (trans- } \\
\text { piceid, glucuronides } \\
\text { and sulfates) }\end{array}$} & \multicolumn{2}{|l|}{ Food group-level $^{b}$} & \multicolumn{2}{|c|}{ Fermentation-dependent } \\
\hline & & \multicolumn{2}{|c|}{ - (Epi)catechin and metabolites (also see cocoa, coffee, tea) } & $\begin{array}{l}\text { - Ethanol } \\
\text { - Ethyl glucuronide } \\
\text { - Ethyl sulfate }\end{array}$ & $\begin{array}{l}\text { - Mannitol } \\
\text { - Gallic acid }\end{array}$ \\
\hline Beer & $\begin{array}{l}\text { - (Iso)xanthohumol } \\
\text { - Iso-alpha-acids } \\
\text { (isohumulones) } \\
\text { - 8-Prenylnaringenin }\end{array}$ & \multirow{2}{*}{\multicolumn{2}{|c|}{$\begin{array}{l}\text { - Alkylresorcinols and metabolites (3,5- } \\
\text { dihydroxybenzoic acid, DHPPA, C17:0 to C21:0 } \\
\text { ratio) } \\
\text { - Benzoxazinoids and related compounds (2- } \\
\text { hydroxyl-1,4-benzoxazin-3-one, hydroxylated } \\
\text { phenylacetamides and derivatives, HHPAA } \\
\text { glucuronide and sulfate) }\end{array}$}} & & -2-Ethyl malate \\
\hline Bread & $\begin{array}{l}\cdot 2,4- \\
\text { Dihydroxybutanoic } \\
\text { acid* } \\
\cdot 2,8^{*} \\
\text { Dihydroxyquinoline } \\
\text { glucuronide* }\end{array}$ & & & - Methionine & \\
\hline Cocoa & - None identified & \multirow{3}{*}{\multicolumn{2}{|c|}{$\begin{array}{l}\text { - Caffeine and metabolites (theophylline, 1- } \\
\text { methylxanthine, 3-methylxanthine, 7- } \\
\text { methylxanthine, paraxanthine, theobromine, } \\
\text { AAMU, AMMU) } \\
\text { - 1-, 3-, or 7-Methyluric acid, 1,3-, 1,7-, or 3,7- } \\
\text { dimethyluric acid, 1,3,7-trimethyluric acid } \\
\text { - Chlorogenic acid, caffeic acids, quinic acids } \\
\text { - Nicotinic acid, hydroxynicotinic acid } \\
\text { - (Epi)catechin, (epi)catechin glucuronide and } \\
\text { metabolites (3-hydroxyhippurate, MHPV, } \\
\text { MHPV sulfate, glucuronide, 4-hydroxy-5-(3,4- } \\
\text { dihydroxyphenyl) valeric acid, 4-hydroxy-5- } \\
\text { (hydroxyphenyl) valeric acid sulfate, DHPV } \\
\text { glucuronide, sulfoglucuronide) }\end{array}$}} & \multirow[t]{2}{*}{ - Acetate/acetic acid } & \\
\hline Coffee & $\begin{array}{l}\text { - Trigonelline } \\
\text { - N-methylpyridinium } \\
\text { - Cyclo(isoleucyl- } \\
\text { prolyl) } \\
\text { - Atractyligenin } \\
\text { glucuronide } \\
\text { - 2-Furoylglycine } \\
\text { - 4-Ethylguaiacol } \\
\text { - 4-Vinylguaiacol }\end{array}$ & & & & \\
\hline $\mathrm{Tea}^{c}$ & $\begin{array}{l}\text { - C-linked dihydro- } \\
\text { chalcone and flava- } \\
\text { none glucosides }\end{array}$ & & & \multicolumn{2}{|l|}{$\begin{array}{l}\text { - Theabrownins } \\
\text { - Gallic acid }\end{array}$} \\
\hline Soyc & - None identified & \multicolumn{2}{|c|}{$\begin{array}{l}\text { - Pinitol } \\
\text { - Isoflavones (daidzein, genistein, glycitein), glycoside-enriched }\end{array}$} & $\begin{array}{l}\text { - Aglycone-enriched } \\
\text { isoflavones and cer- } \\
\text { tain } 4^{\prime} \text { and } 7^{\prime} \text { isofla- } \\
\text { vone metabolites } \\
\text { - Threonine, } \\
\text { Tryptophan, } \\
\text { Tyrosine, Valine } \\
\text { - Vitamin B12 } \\
\text { - Indole-3-lactic acid }\end{array}$ & $\begin{array}{l}\text { - } 4 \text { - } \\
\text { Methylspinacemine } \\
\text { - Menaquinone-7 } \\
\quad \text { (vitamin K2) }\end{array}$ \\
\hline Cheese & $\begin{array}{l}\text { - Isovalerylglutamic } \\
\text { acid } \\
\text { - Isovalerylglycine } \\
\text { - Triglylglycine } \\
\text { - Isobutyrylglycine }\end{array}$ & \multirow{2}{*}{\multicolumn{2}{|c|}{$\begin{array}{l}\text { - Pentadecanoic acid (C15:0) } \\
\text { - Heptadecanoic acid (C17:0) } \\
\text { - 10Z-Heptadecenoic acid (C17:1) } \\
\text { - Myristoyl-sphingomyelin SM(d18:1/14:0) } \\
\text { - Lactose } \\
\text { - Galactitol } \\
\text { - Galactonate } \\
\text { - Galactono-1,5-lactone } \\
\text { - Galactose }\end{array}$}} & $\begin{array}{l}\text {-3-Phenyllactic acid } \\
\text { - Methionine }\end{array}$ & - Lactic acid \\
\hline Yoghurt & - None identified & & & $\begin{array}{l}\text { - Indole-3-lactic acid, } \\
\text { indole-3- } \\
\text { acetaldehyde, } \\
\text { indole-3-propionic } \\
\text { acid }\end{array}$ & \\
\hline
\end{tabular}

AAMU 5-acetylamino-6-amino-3-methyluracil, AMMU 5-acetylamino-6-formylamino-3-methyluracil, DHPV 5-(3,4-dihydroxyphenyl)- - -valerolactone, DHPPA 3-(3,5dihydroxyphenyl)-1-propanoic acid, HHPAA 2-hydroxy- $\mathrm{N}$-(2-hydroxyphenyl) acetamide, LAB lactic acid bacteria, MHPV 3'-methoxy-4'-hydroxyphenylvalerolactone ${ }^{a}$ Wherever possible, the raw material from which the metabolite is derived from, the chemical class, or the fermentation or metabolic process by which the metabolite is generated from, is indicated in square brackets. A full list of references from which these metabolites were derived is provided in Additional Files 3 and 4. The specificity of food-level FIBs for each fermented food (or raw material) was verified through food database searches. Where specificity could not be confirmed, the metabolite is marked with a "*" and further expanded upon in the text

${ }^{\mathrm{b}} \mathrm{A}$ group of foods with a common raw material substrate or characteristic

'Post-fermented tea and fermented soy products

isovalerylglycine, triglylglycine, and isobutyrylglycine were previously identified as specific FIBs for cheese [34]. A large number of phenolic acid, alkaloid, and terpene derivatives have been identified as FIBs of coffee, with trigonelline and cyclo(isoleucylprolyl) emerging as the most specific biomarkers [33]. No specific biomarkers were identified, previously or in the current review, for yoghurt, buttermilk, or cocoa; however, several 
non-specific biomarkers at the food group level were found.

\section{Food group-level biomarkers}

A number of FIBs previously proposed as food-specific markers have been re-classified as discriminant for a group of foods in light of evolving research. For instance, while caffeine has been consistently linked to coffee intake, it is also detected at fairly high concentrations in tea and chocolate [33, 52]. In addition, a growing range of products can be artificially caffeinated, which also obscures the use of caffeine as a FIB for only naturally caffeinated foods. Similarly, the hydroxycinnamate ferulic acid has been detected in high levels in coffee [53], but it is also an antioxidant that is ubiquitously found in plant tissues [54]. Unsurprisingly, increased levels of ferulic acid and its derivatives have been detected in blood and urine following the consumption of multiple plant-based foods $[55,56]$, indicating that the sole use of this compound as a FIB for coffee would be inappropriate. These compounds however may still be useful as food grouplevel biomarkers in conjunction with food-level and/or fermentation-dependent biomarkers for evaluating the intake of fermented foods.

The biomarkers identified at the food group level for different fermented foods are summarized in Table 1 and their relevance discussed below. It is important to note that while we defined "food groups" in the literature search by those conventionally used in dietary recommendation guidelines, food group-level biomarkers may be common across multiple foods based on common substrates of fermentation (e.g., wheat in both beer and bread production), or multiple biomarkers may apply in the case of multiple substrates for a single fermented food (e.g., tarhana, a fermented mixture of cereals and yoghurt). Since fermented beverages encompass a broad, heterogenous group, different fermented beverages are discussed in the context of their fermentation raw material, which includes milk (fermented milks, kefir, and yoghurt-based drinks), fruits (cider, wine, fermented orange juice, fermented beet juice), cereals and grains (beer), and others (coffee, postfermented tea). In many cases, compounds identified at the food group level represented FIBs of unfermented raw material rather than a fermented food group, but nonetheless, their description is important as part of a combined model of fermented food intake.

\section{Fermented dairy}

Several compounds identified in our search were associated with the intake of cheese and yoghurt, including the widely discussed fatty acids heptadecanoic acid (C17:0) and pentadecanoic acid (C15:0). These fatty acids were also captured in the systematic review of egg and dairy biomarkers by Munger et al. [34] as dairy biomarkers, where additional FIBs were proposed for general dairy fat/ dairy products, including 10Z-heptadecenoic acid (C17:1), myristoyl-sphingomyelin SM(d18:1/14:0), and galactonate. A handful of additional compounds that could represent biomarkers for milk (as compared to fermented milk) were additionally identified in the current search, including galactitol, galactonate, galactono-1,5-lactone, galactose, and lactose [57-59]. Collectively, these compounds represent FIBs that may be useful for estimating total dairy intake, including both fermented and non-fermented dairy. As the degree of transformation of lactose (and similar metabolites) greatly varies among dairy products, the profile of these combined metabolites could provide specific insights into the degree of fermentation of the ingested dairy products.

It has been reported that fermentation of milk products may increase the bioavailability of nutritionally important and bioactive compounds of milk [60]. Major milk proteins include caseins ( $\alpha \mathrm{s} 1, \alpha \mathrm{s} 2, \beta$, and k), $\beta$-lactoglobulin, $\alpha$-lactalbumin (precursor of serotonin), immunoglobulins (IgA, IgG, IgM), glycomacropeptide, lactoferrin, lactoperoxidase, lysozyme, and serum albumin [7]. Milk proteins are easily hydrolyzed to free amino acids during fermentation, and a large group of amino acids (alpha-amino butyric acid, alanine, asparagine, cysteine, glycine, glutamine, histidine, isoleucine, leucine, lysine, methionine, ornithine, phenylalanine, proline, serine, threonine, tryptophan, tyrosine, and valine) were found to be increased in plasma following yoghurt and cheese intake compared to control (milk or water) [61-63]. Dairy proteins are also a source of bioactive peptides that can be released during fermentation or during digestion [64,65]. The bioactive peptides derived from these milk proteins during fermentation, such as Isoleucine-Proline-Proline (IPP) and ValineProline-Proline (VPP), are reported to possess antimicrobial, antioxidative, immunomodulatory, angiotensin-1converting enzyme (ACE-1) inhibitory, and renin inhibitory activities [7]. While these peptides were not identified in our search, their presence in fermented dairy products warrants further investigation in a combination biomarker approach for this food group.

\section{Fermented cereals and grains}

Cereals and grains are a staple agricultural product around the world, and their fermentation results in an array of rice-based (idli, dosa), wheat-based (bread, kishk), corn-based (ogi, pozol), or sorghum-based (injera, kisra) dishes [66]. To date, the vast majority of research activity on FIBs of this fermented food group has centered around wheat-based bread products (whole or refined grain) that are leavened with baker's yeast (Saccharomyces cerevisiae), with little to no reports on FIBs for other fermented grains. In the current review, 
alkylresorcinols and their primary metabolites 3,5-dihydroxybenzoic acid (DHBA) and 3-(3,5-dihydroxyphenyl)propanoic acid (DHPPA), as well as benzoxazinoids and their metabolites (2-hydroxyl-1,4-benzoxazin-3-one, hydroxylated phenylacetamides and derivatives thereof), were identified as FIBs of wholegrain wheat/rye [67-72]. Since these compounds are derived from wholegrain wheat and rye, they are present at a higher abundance in biosamples following consumption of wholegrain breads, rather than refined-wheat bread [67]. A recent review focusing on mass spectrometry analysis of whole grains revealed the presence of hundreds of molecules in various wheat, barley, oat, and rye products, including alk(en)ylresorcinols, benzoxazinoids, avenanthramides, flavonoids, lignans, phytosterols, carotenoids, phenolic acids (hydroxybenzoic and hydroxycinnamic acids), sphingolipids, tocols, and glycine betaine [73]. While these compounds have been primarily reported in raw grains and leavened bread products, they may also be useful as FIBs for fermented food products in which grains are used as a starting raw material (e.g., wheat/barley in beer production). It has not yet been investigated whether these compounds can also be detected in soy sauce, which is a fermented mixture of soybeans and wheat [66].

A further distinction should also be made for breads that are leavened solely by yeast, and sourdough breads, which are both leavened by yeast and fermented by LAB. Sourdough-fermented rye has also been shown to contain higher levels of organic acids compared to rye bread, which can reduce starch digestibility and gastric emptying rate, leading to reduced insulin and glucose responses $[74,75]$. In one study, consumption of sourdough fermented bread increased total free amino acids in plasma compared to bread fermented solely with yeast, indicating improved digestibility of protein [76].

\section{Fermented meats and fish}

Fermented meat products are broadly produced and consumed in Germany, France, Spain, Italy, the Balkans, Hungary, Australia, the USA, and Japan [7]. Despite their widespread consumption, no studies were identified in the current search that reported on candidate FIBs of fermented meat or fish. However, a number of studies have identified FIB of raw or unfermented meat and fish products. For example, a study in free-living individuals previously identified candidate biomarkers for chicken (anserine), meat (chicken, red meat, processed meat) (carnosine), fish (trimethylamine-N-oxide), and meat and fish intake (3acetylcarnitines, including acetylcarnitine, propionylcarnitine, and 2-methylbutyrylcarnitine) [77]. In another study, 1- and 3-methylhistidine were determined to be urinary biomarkers for meat intake [78]. Furthermore, raw meat is known to contain the histidyl dipeptides, carnosine and anserine $\mathrm{m}[79]$. FIBs for meat intake were comprehensively evaluated in a review, in which urea, creatine, creatinine, carnitine, carnosine, anserine, ophidine, 1- and 3-methylhistidine, and sulfate or sulfite were described as the most discriminant compounds [80].

For fermented meats, nitrites that are used as curing agents might also be present in some final products [81]. In addition, some fermented sausages have been reported to contain high levels of the biogenic amine tyramine [82] and the antioxidant taurine (2-aminoethane sulfonic acid) $[79,83]$, both of which warrant confirmation as FIBs for fermented meat in human studies. Similarly to fermentation of other high-protein foods, fermentation of meat products also releases bioactive peptides from proteolytic protein degradation. ACE-1 inhibitory peptides and antioxidant peptides have been identified in cured ham and fermented sausages, such as Serbian Petrovac sausage [84] and Spanish dry-cured ham [85-87]. While detected in the foods themselves, no studies were identified in the literature search in which these peptides were identified in biosamples following consumption of fermented meat products. On the other hand, biogenic amines [88] as well as ACE-1 inhibitory peptides [89] are well described in cheese, indicating that the distribution of these molecules extends beyond fermented meat products.

\section{Fermented fruits and vegetables}

While, in theory all fruits and vegetables could be fermented, those most commonly fermented include cabbage (sauerkraut, kimchi), cucumbers, olives, onions, carrots, caper berries, and garlic [90, 91]. Fruits and vegetables are commonly fermented using LAB and yeasts via techniques such as dry salting or storage in a brine [90]. During the lactic fermentation of cucumbers, cabbage, and olives, glucose and fructose are broken down to produce lactic acid, acetic acid, ethanol, and carbon dioxide [91]. The production of organic acids plays a critical role in food safety by limiting the growth of pathogenic microorganisms [90]. Slight differences in the fermentation process can also alter the final metabolite composition and quantities between food products. For instance, fermentation of cabbage into sauerkraut degrades glucosinolates to isothiocyanates, indole-3carbinol, goitrin, allyl cyanide, and nitriles. While the degradation products allyl isothiocyaniate, allyl cyanide, and goitrin were higher in the spontaneously fermented product consisting of salted raw cabbage, methyl isothiocyanate and indole-3-carbinol were higher following in sauerkraut fermented with a starter culture containing LAB [92].

Plasma $\beta$-cryptoxanthin and lutein have been previously proposed as robust biomarkers for general fruit and vegetable intake [93] and have been used to measure dietary compliance in multiple human intervention 
studies. Untargeted metabolomics studies have further revealed a wide range of compounds associated with the intake of plant-based foods [94]. However, from our systematic search, only five studies investigating fermented fruits and vegetables were identified. In one study, Dphenyllactic acid, a LAB metabolite, increased in the serum and urine of four volunteers following acute consumption of sauerkraut [95]. In another study, 20-Obeta-D-glucopyranosyl-20(S)-protopanaxadiol, a novel ginseng saponin metabolite, was increased following intake of fermented ginseng. However, it was reported that the formation of this compound is likely attributable to the action of human intestinal bacteria [96]. Further, it was reported that fermented red cabbage has lower bioavailability of anthocyanins compared to fresh red cabbage [97]. Contrary results were reported in HorneroMendez et al. [98], where bioavailability of betacryptoxanthin and lutein (both attributed to oranges) were higher following consumption of fermented orange juice, and in Sawicki et al. [99], where increased levels of betalain and derivatives in plasma and urine following the consumption of fermented red beet juice were all attributed to red beetroot. However, despite the higher bioavailability afforded by the fermented products, high intake of unfermented forms of these foods would greatly obscure their use as FIBs in dietary assessment.

\section{Fermented legumes and soy}

Although the current search focused on identifying FIBs for all fermented legumes including soy products, only studies on fermented soy products were identified. Soybean products are commonly produced and consumed in East and Southeast Asia and West Africa [4]. Plasma and urinary isoflavones have long been used as markers of soy exposure [100, 101], and more recently, pinitol was identified as a candidate biomarker of soy intake in an untargeted metabolomics study [59]. Although most soy products are characterized by their isoflavone content (which are also present at moderate levels in other legumes), fermented soybeans are comparatively richer than non-fermented soybeans in the isoflavone genestein, as well as gamma-polyglutamic acid (PGA) which is produced by some strains of Bacillus subtilis during fermentation [4]. In addition, the natural isoflavones present in soybeans and unfermented soy products are glucose-conjugated and converted to the aglyconeisoflavones following hydrolysis during digestion prior to absorption [102]. Aglycone-enriched isoflavones that are present in fermented soy products have been reported to be more efficiently absorbed and therefore more bioavailable [102]. In a study by Jang et al. [103], comparing levels of soy isoflavones following ingestion of test meals containing fermented or unfermented soybean, the metabolites daidzein 7-O-glucuronide-4'-O-sulfate and genistein 4',7-di-O-glucuronide were significantly higher in plasma, and genistein 7-Osulfate, glycitein 7-Oglucuronide-4'-O-sulfate, and genistein 4'-O-sulfate were significantly higher in urine, following fermented soy consumption, indicating these metabolites may be useful in distinguishing soy products with different fermentation status. In another acute intervention study, it has been demonstrated that fermentation of soybean increases the urinary recovery of soy isoflavones by $52 \%$ [104]. Analysis of several fermented soy products, including Chungkookjang, tempeh, doenjang, and miso, revealed higher levels of isoflavones (genistin, daidzin, glycitin, genstein, daidzein) and/or amino acids (in particular glutamate) compared to unfermented soybean [105]. In addition to soy isoflavones and aglycones, vitamins B2 and B12, and gamma aminobutyric acid (GABA), are increased in fermented soy products [106], and a variety of bioactive peptides have been identified, such as F2-2-2 and Fr-2-3 in chungkujang, ArginineProline in doenjang, Phenylalanine-Isoleucine-Glycine (1:2:5) in dou-chi, and Valine-Proline-Proline and Isoleucine-Proline-Proline in miso paste containing casein [107-109]. While many of these compounds are present across other foods as well (e.g., vitamin B12), which limits their usefulness as FIBs for fermented soy intake, their combination in a multi-marker approach warrants investigation.

\section{Other fermented products}

Coffee, tea, and chocolate are consumed worldwide, but largely unbeknownst to consumers as "fermented" food products. Unlike yoghurt and cheeses, where the final food products are subject to fermentation and are typically carriers of live microorganisms, fermentation of coffee, tea, and cocoa occurs upstream in the food manufacturing process [110]. Following their harvest, cocoa seeds are intentionally fermented for 7 days [111, 112], raw coffee berries for 10 to 25 days [113], and in the case of post-fermented teas, fresh tea leaves may be fermented from several months up to several years [114]. These foods rely on spontaneous fermentation via the actions of endogenous microbes, and depending on the duration and conditions of the fermentation, different compositional and flavor profiles are attained.

Along with the food-level biomarkers identified for coffee, post-fermented tea, and cocoa as described above, our systematic search revealed several overlapping candidate biomarkers for these foods based on a common raw material characteristic other than a shared substrate. These included caffeine and its metabolites (theobromine, theophylline, methylxanthines, methylurates), nicotinic acid, and multiple phenolic acids, including (epi)catechin, chlorogenic acid, caffeic acids, and quinic acids [94, 115-118] (Table 1). Polyphenols are a group 
of chemically diverse compounds with high abundance in the diet $[115,116]$. Despite the widespread prevalence of polyphenols in a variety of plant-based foods (i.e., coffee, wine, citrus, apples, pears, tea, chocolate), which renders them non-specific biomarkers, distinct polyphenols have been shown to be more closely associated with certain foods than others. For example, methyl-(epi)catechin sulfate has been associated with chocolate intake, hydroxytyrosol, resveratrol, and gallic acid with red wine intake, and (dihydro)ferulic acid and caffeic acid with coffee intake $[115,116]$. Quantification of these polyphenols in biofluids may assist in determining cut-offs or ratios as an indication of their usefulness as biomarkers of acute or habitual intake of these foods. Furthermore, enterolactone, a phytoestrogenic compound formed via gut microbial transformation of plant lignans, has been detected in the blood or urine of individuals following consumption of breads, cocoa, coffee and tea, and soy products. The non-specific nature of this compound limits its usefulness as a specific FIB, but may be interesting to explore as a food group-level biomarker.

\section{Fermentation-dependent biomarkers}

Fermentation of foods is used in part to improve the bioavailability of dietary compounds, or release novel metabolites generated via microbial enzymes [8]. These metabolites that can be considered as potential fermentation-dependent FIBs associated with a dietary pattern of fermented food consumption have not been previously documented in a systematic manner. In this review, we identified several compounds that arise from the fermentation process of a particular food, food group, or different fermented foods possibly indicating fermentation with common microbes.

Several of the potential FIBs identified in this search correspond to specific features of the type of fermentation process or the food that is fermented. Notably, the presence of high levels of the sugar-alcohol mannitol in wine is indicative of fructose degradation during fermentation with LAB $[29,119,120]$, while 2-ethylmalate detected in beer is indicative of yeast fermentation [121]. A significant increase in methionine following sourdough bread [51] and cheese consumption [58] is in line with previous reports of methionine detected in fermented foods, and methionine (and lysine) production by some cultures of Lactobacillus and yeasts used in the fermentation of cereals $[122,123]$.

For tea, an increase in theabrownins (phenolic pigment compounds) reflects the fermentation of catechins and gallate derivatives. Along with acting as a possible FIB for the fermentation process, theabrownins may serve a dual role as health biomarkers as well, as it was recently demonstrated that theabrownins from post-fermented pu-erh tea exerts cholesterol- and lipid-lowering effects via modulation of gut microbiota and bile acid metabolism [124]. Furthermore, increased levels of gallic acid for tea and wine result from the fermentation of the polyphenol EGCG, which is a common food group-level metabolite for these foods $[125,126]$.

Similarly, as a major byproduct of alcoholic fermentation with yeast, ethanol and its metabolites (e.g., ethyl glucuronide, ethyl sulfate) could be considered fermentation biomarkers for alcoholic beverages such as wine, beer, and distilled liquor [127]. Ethanol has been widely used by food and forensic scientists alike to detect and monitor levels of alcohol, typically in blood or expired breath. However, ethanol was not increased in blood following consumption of Şalgam, boza, kimiz, or kefir, which have low alcoholic content due to mainly being fermented with LAB [128]. As such, the utility of ethanol as a biomarker may not extend to low-alcohol beers, dealcoholized wine, or similar variations of these beverages, due to differences in the fermentation process (e.g., selection of yeast strains that do not consume or produce ethanol) or the removal of alcohol from the fermented product.

LAB are used for the fermentation of many food substrates [129], and several classes of compounds are produced via lactic fermentation processes. During fermentation, LAB can convert amino acids into aminecontaining compounds referred to as biogenic amines [130], which can be detected at fairly high concentrations in the final fermented foods. Fermented sausages, for example, have been reported to contain high concentrations of biogenic amines (spermine, spermidine) since their production is primarily attributed to the action of decarboxylase-positive bacteria and meat enzymes during fermentation and ripening [131]. Biogenic amines serve a critical physiological role as precursors for the synthesis of hormones, alkaloids, nucleic acids, and proteins; act as neurotransmitters; and play a role in other central biological functions [132, 133]. While accumulation of biogenic amines in the body has toxicological consequences [130], moderate levels are generally detoxified by amino oxidases in the gut. Despite extensive reports describing the presence of biogenic amines in fermented foods such as cheese, fermented vegetables, wine, and fermented meats, in the current search, only one study reported an increase in spermidine levels (fecal) following yoghurt consumption for 2 to 4mweeks [134, 135], and it is unknown whether this increase is a result of food consumption or synthesis by the gut microbiota. A review of biogenic amines in food products further indicates that biogenic amines are also naturally present in grapes, raw meat and seafood, and fresh milk [136], which offers an explanation of why biogenic amines have not served a prominent role as FIBs for fermented foods. Additionally, biogenic amines are notoriously chemically unstable, as 
well as light- and $\mathrm{pH}$-sensitive, which makes their analysis difficult [137]. However, some research has indicated that further chemical reactions of indoleamines with acetaldehyde can produce novel metabolites during fermentation, ripening, and storage that could be more specific for fermented foods. In a study by Ohya et al. [138], 4methylspinacemine and its metabolite, 1,4-dimethylspinacemine (Pictet-Spengler condensation reaction products of histamine with acetaldehyde), were increased in the urine of volunteers following consumption of soy sauce (with a meal) or Appenzeller cheese. Analysis of various fermented foodstuffs, including soy sauce, fish sauce, cheese, and shao hsing wine, confirmed the presence of both compounds in these foods [138].

A number of vitamins such as folate, vitamin B12, riboflavin, and vitamin $\mathrm{K}$ are produced from fermentation of dairy products, elevating the nutritional quality of the product [7]. In particular, many foods fermented using $B$. subtilis give rise to menaquinone 7 (MK-7, or vitamin $\mathrm{K} 2$ ), which is a long-chain menaquinone primarily synthesized by bacteria and detected abundantly in cheese, as well as fermented soybean products. However, MK-7 can also be synthesized by the gut microbiota, indicating a dual exogenous/endogenous origin of this compound [139]. In the current search, increased MK-7 in serum or plasma was reported following consumption of the fermented soy product, natto [140-143], and validated in cross-sectional studies based on the frequency of natto consumption [141, 143].

Indoles, metabolites derived from tryptophan which act as endogenous ligands for the aryl hydrocarbon receptor, are also known to be produced from LAB via the tryptophanase pathway [144]. In the current review, indoles (especially indole-3-lactic acid) have been detected in biosamples following the consumption of multiple fermented foods, including yoghurt, cheese, beer, coffee, and bread. In addition, multiple strains of LAB produce phenyllactic and 4-hydroxyphenyllactic acids, and these metabolites have been shown to play a role in the quality and preservation of foods [145]. D-phenyllactic acid was increased in serum and urine following the acute consumption of Gruyère cheese $[58,59]$ and in plasma and urine following the acute consumption of sauerkraut [95]. Given that D-phenyllactic acid has also been confirmed to be present in other LAB-fermented foods including kimchi and sourdough [146-148], further investigation is warranted for this metabolite as a promising "fermentationdependent" FIB for lactic-fermented foods.

\section{Heterogeneity of fermented foods and impact on FIBs}

An inherent challenge in searching for FIBs of fermented foods is attributable to the heterogeneity of this food group. As evident in this review, virtually all food substrates can be fermented, and differences in fermentation conditions, such as type of microorganisms involved, duration of fermentation, even minute changes in environmental conditions, further contribute to producing foods with vastly different compositional profiles. To illustrate, consider the fermentation of milk to produce different types of cheeses. The common starting substrate, milk, can originate from cows, goats, sheep, water buffalo, or a combination of these [149]. Some cheeses are ripened with internal (Grana Padano) or surface bacteria (Havarti, Limburger), others with internal molds (Roquefort) or surface (Brie, Camembert) molds [149]. Even within bacteria-ripened cheese, interestingly, the "holes" in the cheese are created via different processes: in Swiss Emmental cheese by fermentation of lactate by Propionibacterium freudenreichii, and in Dutch Gouda cheese by fermentation of citrate by LAB [149].

Aside from the use of different microorganisms, the abundance of microbes can vary widely, and in some cases, the microorganisms are intentionally removed (e.g., heat inactivation, filtration). Even in the absence of a heat or separation step, the number of microbes present at the time of consumption depends on multiple factors, such as the initial composition, storage conditions, and the age of the food [150]. In a review by Rezac et al. [151], levels of live microorganisms in fermented foods were found to be dependent on geographical region and age of the food. For instance, microbial counts were undetectable $\left(<10^{3}\right.$ $\mathrm{cfu} / \mathrm{g})$ in Swiss Gruyère or Grana Padano cheeses aged greater than 1 year, while high counts $\left(10^{9} \mathrm{cfu} / \mathrm{g}\right)$ were found in Tilsit cheese aged for 2 to 4 months [151]. Given that fermentation relies on the enzymatic activities of microorganisms to convert food components, the chances of fermentation-dependent metabolites being detected in biosamples to be identified as FIBs are inevitably linked to the amount of microorganism present in the food product. Furthermore, while industrial fermentations are typically conducted using predefined starter cultures to guarantee consistency, safety, and specific metabolic activities, artisanal fermentations (which are gaining in popularity) rely on mixed sources or microbes endogenous to the raw food [152]. This further complicates the generalizability of any FIBs identified for industrially fermented foods and necessitates careful documentation of fermentation procedures and metabolic products in all cases.

\section{Impact of gut microbiota on FIBs for fermented foods}

A second complexity in exploring FIBs for fermented foods involves the food-gut microbiota interface. Many fermented foods can act as a delivery vehicle for live microorganisms that can subsequently contribute to a changed gut microbiota landscape and altered metabolite appearance $[8,22]$. The diversity of microorganisms found in various fermented foods, as well as their functional properties, have been reviewed previously [22, 
153]. Both the gut and food microbiota can "ferment" food components, and it has recently been documented that over $40 \%$ of the LAB consumed via the ingestion of fermented foods (mainly cheese and other fermented milk products) become members of the gut microbiome [152]. Interestingly, the species of LAB colonized in the gut was found to be regionally dependent, with $S$. thermophiles and lactobacilli linked to yoghurt and dairy product consumption in Western diets, and heterofermentative Leuconostoc and Weissela linked to fermented vegetables and cereal-based foods predominant in nonWestern diets [152]. A further study by Taylor et al. [154] indicated that gut microbiome composition and functional profile are also affected by the frequency of consumption of fermented plants, with several microbes (L. brevis, L. kefiranofaciens, L. parabuchneri, L. helveticus, and L. sakei) associated with both fermented foods and self-reported "consumers," but not "non-consumers" [154]. Furthermore, while transient or long-term intake of fermented foods may differentially impact the gut microbiome, the response of the microbiome to diet remains highly personalized [155]. Collectively, these reports reflect the challenge in delineating the origin of a FIB as from a fermented food, or from a non-fermented food transformed by the gut microbiota.

\section{Representation of fermented foods consumed globally in the literature}

While our goal was to search for FIBs for fermented food products consumed globally, a small number of fermented food products were represented in the current literature. To date, the majority of research has concentrated on coffee, beer, wine, chocolate, bread, and fermented dairy products, as described above. Studies on fermented foods consumed in large quantities in Africa and Asia, for example products from rice (idli, dosa, dhokla), corn (ogi, kenkey, pozol), or sorghum (injera, kisra), fermented alcoholic beverages (sake, bouza, chichi, mahewu, boza) [3-5], were not identified, indicating a gap in the scientific literature. There exists a great opportunity for the further exploration and validation of biomarkers for less-commonly investigated fermented foods, the results of which will help benefit fermentation-dependent FIBs for fermented foods overall.

\section{Conclusions}

The large number of different food-level, food group-level, and fermentation-dependent compounds identified in this literature search may be promising FIBs for fermented food products if combined in a multi-marker approach, and needs to be validated in free-living cohorts with uncontrolled diets. While fairly specific food-level and food group-level biomarkers exist for commonly consumed fermented foods (e.g., trigonelline for coffee, pentadecanoic acid for dairy), this review captured several fermentation-dependent FIBs common among foods fermented by the same fermentation process (e.g., ethanol and metabolites for alcoholic fermentation, methionine, indoles, and 3-phenyllactic acid from lactic fermentation). Further, several gaps in the literature were revealed, particularly in the lack of studies on FIBs for fermented meats, fish, fruits, and vegetables, which presents an opportunity for future scientific investigation. Expanding the repertoire of FIBs for different fermented food products will greatly aid epidemiological efforts aimed to associate fermented foods with various health outcomes.

\section{Abbreviations}

ACE-1: Angiotensin-1-converting enzyme; FIB: Food intake biomarker; FFQ: Food frequency questionnaire; LAB: Lactic acid bacteria

\section{Supplementary Information}

The online version contains supplementary material available at https://doi. org/10.1186/s12263-021-00686-4.

Additional File 1. Food-Specific Keywords Used in the Literature Search for Candidate Biomarkers of Fermented Food Intake.pdf.

Additional File 2. Operators Used in the Literature Search for Candidate Biomarkers of Fermented Food Intake.pdf.

Additional File 3. Summary of Untargeted Studies Presenting Candidate FIBS for Fermented Foods.pdf.

Additional File 4. Summary of Targeted Studies Presenting Candidate FIBs for Fermented Foods.pdf.

\section{Acknowledgements}

Not applicable.

\section{Authors' contributions}

K.J.L defined the search strategy, performed the literature search, and wrote the manuscript. E.M.B-B and K.J.B. defined the search strategy, supervised the project, and critically reviewed the manuscript. G.V. and E.J.M.F were involved in project supervision and critically reviewed the manuscript. All authors reviewed and approved the final manuscript prior to submission.

\section{Funding}

Funding was provided by Agroscope, the Federal Department of Economic Affairs, Education and Research (EAER), Federal Office for Agriculture (FOAG) (Bern, Switzerland), for the Cardioferment Project.

Availability of data and materials Not applicable.

\section{Declarations}

Ethics approval and consent to participate Not applicable.

Consent for publication

Not applicable.

Competing interests

The authors declare that they have no competing interests. 
Received: 18 September 2020 Accepted: 30 March 2021 Published online: 21 April 2021

\section{References}

1. Bourdichon F, Casaregola S, Farrokh C, Frisvad JC, Gerds ML, Hammes WP, et al. Food fermentations: microorganisms with technological beneficial use Int J Food Microbiol. 2012;154(3):87-97. https://doi.org/10.1016/j. ijfoodmicro.2011.12.030.

2. Steinkraus KH. Fermented foods, feeds, and beverages. Biotech Adv. 1986; 4(2):219-43. https://doi.org/10.1016/0734-9750(86)90310-1.

3. Chilton SN, Burton JP, Reid G. Inclusion of fermented foods in food guides around the world. Nutrients. 2015;7(1):390-404. https://doi.org/10.3390/ nu7010390.

4. Anal AK. Quality ingredients and safety concerns for traditional fermented foods and beverages from Asia: a review. Fermentation. 2019;5(8). https:// doi.org/10.3390/fermentation5010008

5. Prakash J. Chapter 14 - safety of fermented cereals and legumes. In: Prakash V, Martin-Belloso O, Keener L, Astley S, Braun S, McMahon H, Lelieveld H, editors. Regulating safety of traditional and ethnic foods. Amsterdam: Elsevier; 2016. p. 283-310. https://doi.org/10.1016/B978-0-12-800605-4. 00014-1.

6. Skåra T, Axelsson L, Stefánsson G, Ekstrand B, Hagen H. Fermented and ripened fish products in the northern European countries. J Ethn Foods. 2015;2(1):18-24. https://doi.org/10.1016/j.jef.2015.02.004.

7. Hayes M, García-Vaquero M. Chapter 14 bioactive compounds from fermented food products. In: Ojha KS, Tiwari BK, editors. Novel food fermentation technologies, Food Engineering Series. Switzerland: Springer International Publishing; 2016. p. 293-310. https://doi.org/10.1007/978-3-31 9-42457-6_14.

8. Marco ML, Heeney D, Binda S, Cifelli CJ, Cotter PD, Foligné B, et al. Health benefits of fermented foods: microbiota and beyond. Curr Opin Biotechnol. 2017;44:94-102. https://doi.org/10.1016/j.copbio.2016.11.010.

9. Meersman E, Steensels J, Mathawan M, Wittocx PJ, Saels V, Struyf N, et al. Detailed analysis of the microbial population in Malaysian spontaneous cocoa pulp fermentations reveals a core and variable microbiota. PLoS One. 2013;8(12):e81559. https://doi.org/10.1371/journal.pone.0081559.

10. De Roos J, De Vuyst L. Acetic acid bacteria in fermented foods and beverages. Curr Opin Biotechnol. 2018;49:115-9. https://doi.org/10.1016/j. copbio.2017.08.007.

11. Sieuwerts S, Bron PA, Smid EJ. Mutually stimulating interactions between lactic acid bacteria and Saccharomyces cerevisiae in sourdough fermentation. LWT Food Sci Technol. 2018;90:201-6. https://doi.org/10.1016/ j.lwt.2017.12.022.

12. Liu Y, Rousseaux S, Tourdot-Maréchal R, Sadoudi M, Gougeon R, SchmittKopplin P, et al. Wine microbiome: a dynamic world of microbial interactions. Crit Rev Food Sci Nutr. 2017;57(4):856-73. https://doi.org/10.1 080/10408398.2014.983591

13. Olmedilla-Alonso B, Jiménez-Colmenero F, Sánchez-Muniz FJ. Development and assessment of healthy properties of meat and meat products designed as functional foods. Meat Sci. 2013;95(4):919-30. https://doi.org/10.1016/j. meatsci.2013.03.030.

14. Raikos V, Dassios T. Health-promoting properties of bioactive peptides derived from milk proteins in infant food: a review. Dairy Sci Technol. 2014; 94(2):91-101. https://doi.org/10.1007/s13594-013-0152-3.

15. Grienke U, Silke J, Tasdemir D. Bioactive compounds from marine mussels and their effects on human health. Food Chem. 2014;142:48-60. https://doi. org/10.1016/j.foodchem.2013.07.027.

16. Marsh AJ, Hill C, Ross RP, Cotter PD. Fermented beverages with health promoting, potential: past and future perspectives. Trends Food Sci Tech. 2014;38(2):113-24. https://doi.org/10.1016/j.tifs.2014.05.002.

17. Limón Rl, Peñas E, Torino Ml, Martínez-Villaluenga C, Dueñas M, Frias J. Fermentation enhances the content of bioactive compounds in kidney bean extracts. Food Chem. 2015;172:343-52. https://doi.org/10.1016/j. foodchem.2014.09.084

18. Shobharani P, Halami PM, Sachindra NM. Potential of marine lactic acid bacteria to ferment Sargassum sp. for enhanced anticoagulant and antioxidant properties. J Appl Microbiol. 2013;114(1):96-107. https://doi. org/10.1111/jam.12023.

19. Barclay W, Apt K, Dong XD. Commercial production of microalgae via fermentation. In: Richmond A, Hu Q, editors. Handbook of microalgal culture: applied phycology and biotechnology (2nd ed.). Oxford: Wiley; 2013. https://doi.org/10.1002/9781118567166.ch9.

20. Chung H-J, Sim J-H, Min T-S, Choi H-K. Metabolomics and lipidomics approaches in the science of probiotics: a review. J Med Food. 2018;21(11): 1086-95. https://doi.org/10.1089/jmf.2017.4175.

21. Steinkraus $\mathrm{KH}$. Classification of fermented foods: worldwide review of household fermentation techniques. Food Control. 1997;8(5/6):311-7. https://doi.org/10.1016/S0956-7135(97)00050-9.

22. Tamang JP, Shin DH, Jung SJ, Chae SW. Functional properties of microorganisms in fermented foods. Front Microbiol. 2016;7:578.

23. Tapsell LC. Fermented dairy food and CVD risk. Brit J Nutr. 2015;113(S2): S131-S5. https://doi.org/10.1017/S0007114514002359.

24. Lordan R, Tsoupras A, Mitra B, Zabetakis I. Dairy fats and cardiovascular disease: do we really need to be concerned? Foods. 2018;7(3). https://doi. org/10.3390/foods7030029.

25. Şanlier N, Gökcen BB, Sezgin AC. Health benefits of fermented foods. Crit Rev Food Sci Nutr. 2019;59(3):506-27. https://doi.org/10.1080/10408398.201 7.1383355 .

26. Brennan L, Hu FB. Metabolomics-based dietary biomarkers in nutritional epidemiology-current status and future opportunities. Mol Nutr Food Res. 2019;63(1):e1701064. https://doi.org/10.1002/mnfr.201701064.

27. Kipnis V, Midthune D, Freedman L, Bingham S, Day NE, Riboli E, et al. Bias in dietary-report instruments and its implications for nutritional epidemiology. Public Health Nutr. 2002;5(6A):915-23. https://doi.org/10.1079/PHN2002383.

28. Brouwer-Brolsma EM, Brennan L, Drevon CA, van Kranen H, Manach C, Dragsted LO, et al. Combining traditional dietary assessment methods with novel metabolomics techniques: present efforts by the Food Biomarker Alliance. Proc Nutr Soc. 2017;76(4):619-27. https://doi.org/10.1017/S002 9665117003949

29. Vázquez-Fresno R, Llorach R, Urpi-Sarda M, Khymenets O, Bulló M, Corella D, et al. An NMR metabolomics approach reveals a combined-biomarkers model in a wine interventional trial with validation in free-living individuals of the PREDIMED study. Metabolomics. 2015;11(4):797-806. https://doi.org/1 0.1007/s11306-014-0735-x.

30. Praticò G, Gao Q, Scalbert A, Vergères $G$, Kolehmainen M, Manach C, et al. Guidelines for Biomarker of Food Intake Reviews (BFIRev): how to conduct an extensive literature search for biomarker of food intake discovery. Genes Nutr. 2018;13(1):3. https://doi.org/10.1186/s12263-018-0592-8.

31. Dragsted LO, Gao Q, Scalbert A, Vergères G, Kolehmainen M, Manach C, et al. Validation of biomarkers of food intake-critical assessment of candidate biomarkers. Genes Nutr. 2018;13(1):14. https://doi.org/10.1186/ s12263-018-0603-9.

32. Michielsen C, Almanza-Aguilera E, Brouwer-Brolsma EM, Urpi-Sarda M, Afman LA. Biomarkers of food intake for cocoa and liquorice (products): a systematic review. Genes Nutr. 2018;13:13.

33. Rothwell JA, Madrid-Gambin F, Garcia-Aloy M, Andres-Lacueva C, Logue C, Gallagher AM, et al. Biomarkers of intake for coffee, tea, and sweetened beverages. Genes Nutr. 2018;13(1):15. https://doi.org/10.1186/s12263-0180607-5.

34. Münger LH, Garcia-Aloy M, Vázquez-Fresno R, Gille D, Rosana ARR, Passerini A, et al. Biomarker of food intake for assessing the consumption of dairy and egg products. Genes Nutr. 2018;13:18.

35. Praticò G, Gao Q, Manach C, Dragsted LO. Biomarkers of food intake for Allium vegetables. Genes Nutr. 2018;13(1):34. https://doi.org/10.1186/s12263018-0624-4.

36. Sri Harsha PSC, Wahab RA, Garcia-Aloy M, Madrid-Gambin F, Estruel-Amades S, Watzl B, et al. Biomarkers of legume intake in human intervention and observational studies: a systematic review. Genes Nutr. 2018;13(1):25. https:// doi.org/10.1186/s12263-018-0614-6.

37. Ulaszewska M, Vázquez-Manjarrez N, Garcia-Aloy M, Llorach R, Mattivi F, Dragsted LO, et al. Food intake biomarkers for apple, pear, and stone fruit. Genes Nutr. 2018;13(1):29. https://doi.org/10.1186/s12263-018-0620-8.

38. Garcia-Aloy M, Hulshof PJM, Estruel-Amades S, Osté MCJ, Lankinen M, Geleijnse JM, et al. Biomarkers of food intake for nuts and vegetable oils: an extensive literature search. Genes Nutr. 2019;14(1):7. https://doi.org/10.1186/ s12263-019-0628-8.

39. Vázquez-Fresno R, Rosana ARR, Sajed T, Onookome-Okome T, Wishart NA, Wishart DS. Herbs and spices-biomarkers of intake based on human intervention studies - a systematic review. Genes Nutr. 2019;14(1):18, Herbs and Spices- Biomarkers of Intake Based on Human Intervention Studies - A Systematic Review. https://doi.org/10.1186/s12263-019-0636-8. 
40. Zhou X, Gao Q, Praticò G, Chen J, Dragsted LO. Biomarkers of tuber intake. Genes Nutr. 2019;14(1):9. https://doi.org/10.1186/s12263-019-0631-0.

41. Moher D, Liberati A, Tetzlaff J, Altman DG, Group P. Preferred reporting items for systematic reviews and meta-analyses: the PRISMA statement. Ann Intern Med. 2009;151(4):264-9, W64. https://doi.org/10.7326/0003-4819-1 51-4-200908180-00135.

42. The Netherlands Nutrition Centre. Richtlijnen Schijf van Vijf (Guidelines Wheel of Five). Den Haag: Voedingscentrum; 2016. Available from: https:// www.voedingscentrum.nl/. Accessed 8 Aug 2019

43. Swiss Society for Nutrition. Schweizer Lebensmittelpyramide (Swiss Food Pyramid). Schweizerische Gesellschaft für Ernährung, Bern, Switzerland. Available from: http://www.sge612 ssn.ch/lebensmittelpyramide. Accessed 8 Aug 2019.

44. U.S. Department of Health and Human Services and U.S. Department of Agriculture. 2015-2020 Dietary Guidelines for Americans. 8th ed. Washington, DC: U.S. Department of Health and Human Services; 2015. Available from: https://health.gov/dietaryguidelines/2015/guidelines/. Accessed 8 Aug 2019

45. Regueiro J, Vallverdú-Queralt A, Simal-Gándara J, Estruch R, LamuelaRaventós RM. Urinary tartaric acid as a potential biomarker for the dietary assessment of moderate wine consumption: a randomised controlled trial. Br J Nutr. 2014;111(9):1680-5. https://doi.org/10.1017/S0007114513004108.

46. Zamora-Ros R, Urpí-Sardà M, Lamuela-Raventós RM, Estruch R, VázquezAgell M, Serrano-Martínez M, et al. Diagnostic performance of urinary resveratrol metabolites as a biomarker of moderate wine consumption. Clin Chem. 2006;52(7):1373-80. https://doi.org/10.1373/clinchem.2005.065870.

47. Zamora-Ros R, Urpí-Sardà M, Lamuela-Raventós RM, Estruch R, MartínezGonzález MA, Bulló M, et al. Resveratrol metabolites in urine as a biomarker of wine intake in free-living subjects: the PREDIMED Study. Free Radic Biol Med. 2009;46(12):1562-6. https://doi.org/10.1016/j.freeradbiomed.2008.12. 023.

48. Zamora-Ros R, Rothwell JA, Achaintre D, Ferrari P, Boutron-Ruault M-C, Mancini FR, et al. Evaluation of urinary resveratrol as a biomarker of dietary resveratrol intake in the European Prospective Investigation into Cancer and Nutrition (EPIC) study. Br J Nutr. 2017;117(11):1596-602. https://doi.org/10.1 017/S0007114517001465.

49. Heinzmann SS, Holmes E, Kochhar S, Nicholson JK, Schmitt-Kopplin P. 2Furoylglycine as a candidate biomarker of coffee consumption. J Agric Food Chem. 2015;63(38):8615-21. https://doi.org/10.1021/acs.jafc.5b03040.

50. Midttun O, Ulvik A, Nygård O, Ueland PM. Performance of plasma trigonelline as a marker of coffee consumption in an epidemiologic setting. Am J Clin Nutr. 2018;107(6):941-7. https://doi.org/10.1093/ajcn/nqy059.

51. Bondia-Pons I, Nordlund E, Mattila I, Katina K, Aura AM, Kolehmainen M, et al. Postprandial differences in the plasma metabolome of healthy Finnish subjects after intake of a sourdough fermented endosperm rye bread versus white wheat bread. Nutr J. 2011;10(1).

52. Mayorga-Gross AL, Esquivel P. Impact of cocoa products intake on plasma and urine metabolites: a review of targeted and non-targeted studies in humans. Nutrients. 2019;11(5). https://doi.org/10.3390/nu11051163.

53. Renouf M, Guy PA, Marmet C, Fraering A-L, Longet K, Moulin J, et al. Measurement of caffeic and ferulic acid equivalents in plasma after coffee consumption: small intestine and colon are key sites for coffee metabolism. Mol Nutr Food Res. 2010;54(6):760-6. https://doi.org/10.1002/mnfr.2 00900056.

54. Mathew S, Abraham TE. Ferulic acid: an antioxidant found naturally in plant cell walls and feruloyl esterases involved in its release and their applications. Crit Rev Biotechnol. 2004;24(2-3):59-83. https://doi.org/10.1080/07388550490491467.

55. Bourne L, Paganga G, Baxter D, Hughes P, Rice-Evans C. Absorption of ferulic acid from low-alcohol beer. Free Radic Res. 2000;32(3):273-80. https://doi.org/10.1080/10715760000300281

56. Dall'Asta M, Calani L, Tedeschi M, Jechiu L, Brighenti F, Del Rio D. Identification of microbial metabolites derived from invitro fecal fermentation of different polyphenolic food sources. Nutrition. 2012;28(2): 197-203. https://doi.org/10.1016/j.nut.2011.06.005.

57. Pimentel G, Burton KJ, von Ah U, Bütikofer U, Pralong FP, Vionnet N, et al. Metabolic footprinting of fermented milk consumption in serum of healthy men. J Nutr. 2018;148(6):851-60. https://doi.org/10.1093/jn/nxy053.

58. Trimigno A, Münger L, Picone G, Freiburghaus C, Pimentel G, Vionnet N, et al. GC-MS based metabolomics and NMR spectroscopy investigation of food intake biomarkers for milk and cheese in serum of healthy humans. Metabolites. 2018;8(2).
59. Münger LH, Trimigno A, Picone G, Freiburghaus C, Pimentel G, Burton K, et al. Identification of urinary food intake biomarkers for milk, cheese, and soy-based drink by untargeted GC-MS and NMR in healthy humans. J Proteome Res. 2017;16(9):3321-35. https://doi.org/10.1021/acs.jproteome. $7 b 00319$.

60. Ebringer $L$, Ferenčík $M$, Krajčovič J. Beneficial health effects of milk and fermented dairy products - review. Folia Microbiologica. 2008;53(5):378-94 https://doi.org/10.1007/s12223-008-0059-1.

61. Dougkas A, Minihane AM, Givens DI, Reynolds CK, Yaqoob P. Differential effects of dairy snacks on appetite, but not overall energy intake. Br J Nutr. 2012;108(12):2274-85. https://doi.org/10.1017/S0007114512000323.

62. Pimentel G, Burnand D, Münger LH, Pralong FP, Vionnet N, Portmann R, et al. Identification of milk and cheese intake biomarkers in healthy adults reveals high interindividual variability of Lewis system-related oligosaccharides. J Nutr. 2020;150(5):1058-67. https://doi.org/10.1093/jn/ nxaa029.

63. Chandan RC. Dairy - fermented products. In: Clark S, Jung S, Lamsal B, editors. Food processing: principles and applications. 2nd ed. Oxford: Wiley, Ltd; 2014. p. 405-36.

64. Seppo $L$, Jauhiainen $T$, Poussa $T$, Korpela R. A fermented milk high in bioactive peptides has a blood pressure-lowering effect in hypertensive subjects. Am J Clin Nutr. 2003;77(2):326-30. https:/doi.org/10.1093/ajcn/77.2.326.

65. Beltrán-Barrientos LM, Hernández-Mendoza A, Torres-Llanez MJ, GonzálezCórdova AF, Vallejo-Córdoba B. Invited review: fermented milk as antihypertensive functional food. J Dairy Sci. 2016;99(6):4099-110. https:// doi.org/10.3168/jds.2015-10054.

66. Blandino A, Al-Aseeri ME, Pandiella SS, Cantero D, Webb C. Cereal-based fermented foods and beverages. Food Res Int. 2003;36(6):527-43. https:// doi.org/10.1016/S0963-9969(03)00009-7.

67. Hanhineva K, Keski-Rahkonen P, Lappi J, Katina K, Pekkinen J, Savolainen O, et al. The postprandial plasma rye fingerprint includes benzoxazinoidderived phenylacetamide sulfates. J Nutr. 2014;144(7):1016-22. https://doi. org/10.3945/jn.113.187237.

68. Hanhineva K, Lankinen MA, Pedret A, Schwab U, Kolehmainen M, Paananen $J$, et al. Nontargeted metabolite profiling discriminates diet-specific biomarkers for consumption of whole grains, fatty fish, and bilberries in a randomized controlled trial. J Nutr. 2015;145(1):7-17. https://doi.org/10.394 5/jn.114.196840.

69. Söderholm PP, Koskela AH, Lundin JE, Tikkanen MJ, Adlercreutz HC. Plasma pharmacokinetics of alkylresorcinol metabolites: new candidate biomarkers for whole-grain rye and wheat intake. Am J Clin Nutr. 2009;90(5):1167-71. https://doi.org/10.3945/ajen.2009.28290.

70. Söderholm PP, Lundin JE, Koskela AH, Tikkanen MJ, Adlercreutz HC. Pharmacokinetics of alkylresorcinol metabolites in human urine. Brit J Nutr. 2011;106(7):1040-4. https://doi.org/10.1017/S0007114511001383.

71. Beckmann M, Lloyd AJ, Haldar S, Seal C, Brandt K, Draper J. Hydroxylated phenylacetamides derived from bioactive benzoxazinoids are bioavailable in humans after habitual consumption of whole grain sourdough rye bread. Mol Nutr Food Res. 2013:57(10):1859-73. https://doi.org/10.1002/mnfr.201200777.

72. Garcia-Aloy M, Llorach R, Urpi-Sarda M, Tulipani S, Salas-Salvadó J, MartínezGonzález MA, et al. Nutrimetabolomics fingerprinting to identify biomarkers of bread exposure in a free-living population from the PREDIMED study cohort. Metabolomics. 2014;11(1):155-65.

73. Koistinen VM, Hanhineva K. Mass spectrometry-based analysis of wholegrain phytochemicals. Crit Rev Food Sci Nutr. 2017;57(8):1688-709. https:// doi.org/10.1080/10408398.2015.1016477.

74. Liljeberg HG, Lönner CH, Björck IM. Sourdough fermentation or addition of organic acids or corresponding salts to bread improves nutritional properties of starch in healthy humans. J Nutr. 1995;125(6):1503-11. https:// doi.org/10.1093/jn/125.6.1503.

75. Najjar AM, Parsons PM, Duncan AM, Robinson LE, Yada RY, Graham TE. The acute impact of ingestion of breads of varying composition on blood glucose, insulin and incretins following first and second meals. Brit J Nutr. 2009;101(3):391-8. https://doi.org/10.1017/S0007114508003085.

76. Rizzello CG, Portincasa P, Montemurro M, Di Palo DM, Lorusso MP, De Angelis $M$, et al. Sourdough fermented breads are more digestible than those started with Baker's yeast alone: an in vivo challenge dissecting distinct gastrointestinal responses. Nutrients. 2019;11(12).

77. Cheung W, Keski-Rahkonen P, Assi N, Ferrari P, Freisling H, Rinaldi S, et al. A metabolomic study of biomarkers of meat and fish intake. Am J Clin Nutr. 2017;105(3):600-8. https://doi.org/10.3945/ajcn.116.146639. 
78. Cross AJ, Major JM, Sinha R. Urinary biomarkers of meat consumption. Cancer Epidemiol Biomarkers Prev. 2011;20(6):1107-11. https://doi.org/10.11 58/1055-9965.EPI-11-0048.

79. Bou R, Cofrades C, Jiménez-Colmenero F. Chapter 10: fermented meat sausages. In: Frias J, Martinez-Villaluenga C, Peñas E, editors. Fermented foods in health and disease prevention. Amsterdam: Elsevier; 2017. p. 20335. https://doi.org/10.1016/B978-0-12-802309-9.00010-8.

80. Dragsted LO. Biomarkers of meat intake and the application of nutrigenomics. Meat Sci. 2010;84(2):301-7. https://doi.org/10.1016/j.meatsci.2 009.08.028.

81. Vignolo G, Fontana C, Fadda S. Chapter 22 semidry and dry fermented sausages. In: Toldrá F, editor. Handbook of meat processing. lowa: Blackwell Publishing; 2010. p. 379-98. https://doi.org/10.1002/9780813820897.ch22.

82. Komprda T, Neznalovà J, Standara S, Bover-Cid S. Effect of starter culture and storage temperature on the content of biogenic amines in dry fermented sausage poličan. Meat Sci. 2001;59(3):267-76. https://doi.org/10.1 016/S0309-1740(01)00079-1.

83. Reig M, Aristoy MC, Toldra F. Variability in the contents of pork meat nutrients and how it may affect food composition databases. Food Chem. 2013;140(3):478-82. https://doi.org/10.1016/j.foodchem.2012.11.085.

84. Ferranti P, Nitride C, Nicolai M. A., Mamone, G., Picariello, G., Bordoni, A., et al. In vitro digestion of Bresaola proteins and release of potential bioactive peptides. Food Res Int. 2014;63:157-69. https://doi.org/10.1016/j. foodres.2014.02.008.

85. Escudero E, Mora L, Fraser PD, Aristoy MC, Arihara K, Toldrá F. Purification and identification of antihypertensive peptides in Spanish dry-cured ham. J Proteomics. 2013;78:499-507. https://doi.org/10.1016/j.jprot.2012.10.019.

86. Escudero E, Mora L, Toldrá F. Stability of ACE inhibitory ham peptides against heat treatment and in vitro digestion. Food Chem. 2014;161:305-11. https://doi.org/10.1016/j.foodchem.2014.03.117.

87. Gallego M, Mora L, Aristoy MC, Toldrá F. Titin-derived peptides as processing time markers in dry-cured ham. Food Chem. 2015;167:326-39. https://doi.org/10.1016/j.foodchem.2014.06.088.

88. Chang SF, Ayres JW, Sandine WE. Analysis of cheese for histamine, tyramine, tryptamine, histidine, tyrosine, and tryptophane. J Dairy Sci. 1985;68(11): 2840-6. https://doi.org/10.3168/jds.S0022-0302(85)81176-0.

89. Hernández-Galán L, Cardador-Martínez A, Picque D, Spinnler HE, López-delCastillo Lozano M. and Martín del Campo ST. Angiotensin converting enzyme inhibitors and antioxidant peptides release during ripening of Mexican Cotija hard cheese. J Food Res. 2016;5(3):85-91. https://doi.org/10. 5539/jfr.v5n3p85.

90. Medina E, de Castro A, Romero C, Ramirez EM, Brenes M. Chapter 18: safety of fermented fruits and vegetables. In: Prakash V, Martin-Belloso O, Keener L, Astley S, Braun S, McMahon H, Lelieveld H, editors. Regulating safety of traditional and ethnic foods. Amsterdam, The Netherlands: Elsevier; 2016. p. 355-67. https://doi.org/10.1016/B978-0-12-800605-4.00018-9.

91. Breidt F, McFeeters RF, Perez-Diaz I, Lee CH. Fermented vegetables. In: Doyle MP, Buchanan RL, editors. Food microbiology: fundamentals and frontiers. 4th ed. Washington, D.C.: ASM Press; 2013. p. 841-55.

92. Tolonen M, Taipale M, Viander B, Pihlava JM, Korhonen H, Ryhänen EL. Plant-derived biomolecules in fermented cabbage. J Agric Food Chem. 2002;50(23):6798-803. https://doi.org/10.1021/jf0109017.

93. Couillard C, Lemieux S, Vohl MC, Couture P, Lamarche B. Carotenoids as biomarkers of fruit and vegetable intake in men and women. $\mathrm{Br} \mathrm{J}$ Nutr. 2016;116(7):1206-15. https://doi.org/10.1017/S0007114516003056.

94. Andersen M-BS, Kristensen M, Manach C, Pujos-Guillot E, Poulsen SK, Larsen $\mathrm{TM}$, et al. Discovery and validation of urinary exposure markers for different plant foods by untargeted metabolomics. Anal Bioanal Chem. 2014;406(7): 1829-44. https://doi.org/10.1007/s00216-013-7498-5.

95. Peters A, Krumbholz P, Jäger E, Heintz-Buschart A, Çakir MV, Rothemund S, et al. Metabolites of lactic acid bacteria present in fermented foods are highly potent agonists of human hydroxycarboxylic acid receptor 3. PLoS Genet. 2019;15(5):e1008145. https://doi.org/10.1371/journal.pgen.1008145.

96. Jin H, Seo J-H, Uhm Y-K, Jung C-Y, Lee S-K, Yim S-V. Pharmacokinetic comparison of ginsenoside metabolite $\mathrm{IH}-901$ from fermented and nonfermented ginseng in healthy Korean volunteers. J Ethnopharmacol. 2012; 139(2):664-7. https://doi.org/10.1016/j.jep.2011.11.052.

97. Wiczkowski W, Szawara-Nowak D, Romaszko J. The impact of red cabbage fermentation on bioavailability of anthocyanins and antioxidant capacity of human plasma. Food Chem. 2016;190:730-40. https://doi.org/10.1016/j. foodchem.2015.06.021.
98. Hornero-Méndez D, Cerrillo I, Ortega A, Rodríguez-Griñolo M-R, EscuderoLópez B, Martín F, et al. beta-Cryptoxanthin is more bioavailable in humans from fermented orange juice than from orange juice. Food Chem. 2018;262: 215-20.

99. Sawicki T, Topolska J, Romaszko E, Wiczkowski W. Profile and content of betalains in plasma and urine of volunteers after long-term exposure to fermented red beet juice. J Agric Food Chem. 2018;66(16):4155-63. https:// doi.org/10.1021/acs.jafc.8b00925.

100. Ritchie MRMM, Deighton N, Blake A, Steel M, Cummings JH. Plasma and urine concentrations of isoflavones as biomarkers of phyto-oestrogen intake following dietary soy supplementation. J Evid-Based Integr Med. 2004;1(2): 101-12. https://doi.org/10.2165/01197065-200401020-00004.

101. Morimoto Y, Beckford F, Franke AA, Maskarinec G. Urinary isoflavonoid excretion as a biomarker of dietary soy intake during two randomized soy trials. Asia Pac J Clin Nutr. 2014;23(2):205-9. https://doi.org/10.6133/apjen.2 014.23.2.19.

102. Kano M, Takayanagi T, Harada K, Sawada S, Ishikawa F. Bioavailability of isoflavones after ingestion of soy beverages in healthy adults. J Nutr. 2006; 136(9):2291-6. https://doi.org/10.1093/jn/136.9.2291.

103. Jang HH, Noh H, Kim HW, Cho SY, Kim HJ, Lee SH, et al. Metabolic tracking of isoflavones in soybean products and biosamples from healthy adults after fermented soybean consumption. Food Chem. 2020;330:127317. https://doi.org/10.1016/j.foodchem.2020.127317.

104. de Oliveira SF, Lemos TC, Sandôra D, Monteiro M, Perrone D. Fermentation of soybean meal improves isoflavone metabolism after soy biscuit consumption by adults. J Sci Food Agric. 2020;100(7):2991-8.

105. Kwon DY, Daily JW 3rd, Kim HJ, Park S. Antidiabetic effects of fermented soybean products on type 2 diabetes. Nutr Res. 2010;30(1):1-13. https://doi. org/10.1016/j.nutres.2009.11.004.

106. Xu L, Cai WX, Xu BJ. A systematic assesment on vitamins (B2, B12) and GABA profiles in fermented soy products marketed in China. J Food Process Preserv. 2017:41(5):e13126. https://doi.org/10.1111/jfpp.13126.

107. Zhang JH, Tatsumi E, Chang HD, Li LT. Angiotensin I-converting enzyme inhibitory peptides in douchi, a Chinese traditional fermented soybean product. Food Chem. 2006;98(3):551-7. https:/doi.org/10.1016/j.foodchem.2005.06.024.

108. Inoue K, Gotou T, Kitajima H, Mizuno S, Nakazawa T, Yamamoto N. Release of antihypertensive peptides in miso paste during its fermentation, by the addition of casein. J Biosci Bioeng. 2009;108(2):111-5. https://doi.org/10.101 6/j.jbiosc.2009.03.007.

109. Jayachandran M, Xu B. An insight into the health benefits of fermented soy products. Food Chem. 2019;271:362-71. https://doi.org/10.1016/j. foodchem.2018.07.158.

110. Wilburn JR, Ryan EP. Chapter 1 fermented foods in health promotion and disease prevention: an overview. In: Frias J, Martinez-Villaluenga C, Peñas E, editors. Fermented foods in health and disease prevention. Amsterdam: Elsevier; 2017. p. 3-19. https://doi.org/10.1016/B978-0-12-802309-9.00001-7.

111. Schwan RF, Wheals AE. The microbiology of cocoa fermentation and its role in chocolate quality. Crit Rev Food Sci Nutr. 2004;44(4):205-21. https://doi. org/10.1080/10408690490464104.

112. De Vuyst L, Weckx S. The cocoa bean fermentation process: from ecosystem analysis to starter culture development. J Appl Microbiol. 2016;121(1):5-17. https://doi.org/10.1111/jam.13045.

113. Huch M, Franz CMAP. Coffee: fermentation and microbiota. In: Holzapfel W, editor. Advances in fermented foods and beverages. Amsterdam: Elsevier; 2015. p. 501-13. https://doi.org/10.1016/B978-1-78242-015-6.00021-9.

114. Zhang Y, Skaar I, Sulyok M, Liu X, Rao M, Taylor JW. The microbiome and metabolites in fermented pu-erh tea as revealed by high-throughput sequencing and quantitative multiplex metabolite analysis. PLoS One. 2016; 11(6):e0157847. https://doi.org/10.1371/journal.pone.0157847.

115. Noh H, Freisling $H$, Assi N, Zamora-Ros R, Achaintre D, Affret A, et al. Identification of urinary polyphenol metabolite patterns associated with polyphenol-rich food intake in adults from four European countries. Nutrients. 2017;9(8). https://doi.org/10.3390/nu9080796.

116. Edmands WM, Ferrari P, Rothwell JA, Rinaldi S, Slimani N, Barupal DK, et al. Polyphenol metabolome in human urine and its association with intake of polyphenol-rich foods across European countries. Am J Clin Nutr. 2015; 102(4):905-13. https://doi.org/10.3945/ajcn.114.101881.

117. Cornelis MC, Erlund I, Michelotti GA, Herder C, Westerhuis JA, Tuomilehto J. Metabolomic response to coffee consumption: application to a three-stage clinical trial. J Intern Med. 2018;283(6):544-57. https://doi.org/10.1111/ joim.12737. 
118. Xie G, Zhao A, Zhao L, Chen T, Chen H, Qi X, et al. Metabolic fate of tea polyphenols in humans. J Proteome Res. 2012;11(6):3449-57. https://doi. org/10.1021/pr300318m.

119. Vázquez-Fresno R, Llorach R, Alcaro F, Rodríguez MA, Vinaixa M, ChivaBlanch $\mathrm{G}$, et al. 1H-NMR-based metabolomic analysis of the effect of moderate wine consumption on subjects with cardiovascular risk factors. Electrophoresis. 2012;33(15):2345-54. https://doi.org/10.1002/elps.201100646.

120. Vázquez-Fresno R, Llorach R, Perera A, Mandal R, Feliz M, Tinahones FJ, et al. Clinical phenotype clustering in cardiovascular risk patients for the identification of responsive metabotypes after red wine polyphenol intake. J Nutr Biochem. 2016;28:114-20. https://doi.org/10.1016/j.jnutbio.2015.10.002.

121. Gürdeniz G, Jensen MG, Meier S, Bech L, Lund E, Dragsted LO. Detecting beer intake by unique metabolite patterns. J Proteome Res. 2016;15(12): 4544-56. https://doi.org/10.1021/acs.jproteome.6b00635.

122. Landaud S, Helinck S, Bonnarme P. Formation of volatile sulfur compounds and metabolism of methionine and other sulfur compounds in fermented food. Appl Microbiol Biotechnol. 2008;77(6):1191-205. https://doi.org/10.1 007/s00253-007-1288-y.

123. Odunfa SA, Adeniran SA, Teniola NJ. Evaluation of lysine and methionine production in some Lactobacilli and yeasts from ogi. Int J Food Microbiol. 2001;63(1-2):159-63. https://doi.org/10.1016/S0168-1605(00)00320-2.

124. Huang F, Zheng X, Ma X, Jiang R, Zhou W, Zhou S, et al. Theabrownin from Pu-erh tea attenuates hypercholesterolemia via modulation of gut microbiota and bile acid metabolism. Nat Commun. 2019;10(1):4971. https:// doi.org/10.1038/s41467-019-12896-X.

125. Xie G, Ye M, Wang Y, Ni Y, Su M, Huang H, et al. Characterization of pu-erh tea using chemical and metabolic profiling approaches. J Agric Food Chem. 2009;57(8):3046-54. https://doi.org/10.1021/jf804000y.

126. Urpi-Sarda M, Boto-Ordoñez M, Queipo-Ortuño MI, Tulipani S, Corella D, Estruch R, et al. Phenolic and microbial-targeted metabolomics to discovering and evaluating wine intake biomarkers in human urine and plasma. Electrophoresis. 2015;36(18):2259-68. https://doi.org/10.1002/elps.201400506.

127. Mitchell MC Jr, Teigen EL, Ramchandani VA. Absorption and peak blood alcohol concentration after drinking beer, wine, or spirits. Alcohol Clin Exp Res. 2014;38(5):1200-4. https://doi.org/10.1111/acer.12355.

128. Turner PC, Rothwell JA, White KLM, Gong Y, Cade JE, Wild CP. Urinary deoxynivalenol is correlated with cereal intake in individuals from the United Kingdom. Environ Health Perspect. 2008;116(1):21-5. https://doi. org/10.1289/ehp.10663.

129. Pessione E, Cirrincione S. Bioactive molecules released in food by lactic acid bacteria: encrypted peptides and biogenic amines. Front Microbiol. 2016;7:876.

130. Spano G, Russo P, Lonvaud-Funel A, Lucas P, Alexandre H, Grandvalet C, et al. Biogenic amines in fermented foods. Eur J Clin Nutr. 2010;64(Suppl 3): S95-100. https://doi.org/10.1038/ejcn.2010.218

131. Ruiz-Capillas $C$, Jiménez-Colmenero F. Biogenic amines in meat and meat products. Crit Rev Food Sci Nutr. 2004;44(7-8):489-99. https://doi.org/10.1 080/10408690490489341.

132. Premont RT, Gainetdinov RR, Caron MG. Following the trace of elusive amines. Proc Natl Acad Sci U S A. 2001;98(17):9474-5. https://doi.org/10.1 073/pnas.181356198.

133. Igarashi K, Ito K, Kashiwagi K. Polyamine uptake systems in Escherichia coli. Res Microbiol. 2001;152(3-4):271-8. https://doi.org/10.1016/S0923-2508(01)01198-6.

134. Matsumoto M, Aranami A, Ishige A, Watanabe K, Benno Y. LKM512 yogurt consumption improves the intestinal environment and induces the T-helper type 1 cytokine in adult patients with intractable atopic dermatitis. Clin Exp Allergy. 2007;37(3):358-70. https://doi.org/10.1111/j.1365-2222.2007.02642.x.

135. Matsumoto M, Benno Y. Anti-inflammatory and antimutagenic activity of polyamines produced by Bifidobacterium lactis LKM512. Curr Top Nutraceutical Res. 2004;2(4):219-26.

136. Doeun D, Davaatseren M, Chung MS. Biogenic amines in foods. Food Sci Biotechnol. 2017;26(6):1463-74. https://doi.org/10.1007/s10068-017-0239-3.

137. Plenis A, Olędzka I, Kowalski P, Miękus N, Bączek T. Recent trends in the quantification of biogenic amines in biofluids as biomarkers of various disorders: a review. J Clin Med. 2019;8(5). https://doi.org/10.3390/jcm8050640.

138. Ohya T. Identification of 4-methylspinaceamine, a pictet-spengler condensation reaction product of histamine with acetaldehyde, in fermented foods and its metabolite in human urine. J Agric Food Chem. 2006;54(18):6909-15. https://doi.org/10.1021/jf061364z.

139. Walther B, Chollet M. Menaquinones, bacteria, and foods: vitamin K2 in the diet, vitamin K2 - vital for health and wellbeing, Jan Oxholm Gordeladze. IntechOpen. 2017. https://doi.org/10.5772/63712.
140. Schurgers $L$, Vermeer $C$. Determination of phylloquinone and menaquinones in food. Effect of food matrix on circulating vitamin $\mathrm{K}$ concentrations. Haemostasis. 2000;30(6):298-307. https://doi.org/10.1159/ 000054147.

141. Kaneki M, Hodges SJ, Hosoi T, Fujiwara S, Lyons A, Crean SJ, et al. Japanese fermented soybean food as the major determinant of the large geographic difference in circulating levels of vitamin K2: possible implications for hipfracture risk. Nutrition. 2001;17(4):315-21. https://doi.org/10.1016/S08999007(00)00554-2.

142. Homma K, Wakana N, Suzuki Y, Nukui M, Daimatsu T, Tanaka E, et al. Treatment of natto, a fermented soybean preparation, to prevent excessive plasma vitamin $\mathrm{K}$ concentrations in patients taking warfarin. J Nutr Sci Vitaminol (Tokyo). 2006;52(5):297-301. https://doi.org/10.3177/jnsv.52.297.

143. Tsukamoto Y, Ichise H, Kakuda H, Yamaguchi M. Intake of fermented soybean (natto) increases circulating vitamin K2 (menaquinone-7) and gamma-carboxylated osteocalcin concentration in normal individuals. J Bone Miner Metab. 2000;18(4):216-22. https://doi.org/10.1007/s00774 0070023.

144. Hubbard TD, Murray IA, Perdew GH. Indole and tryptophan metabolism: endogenous and dietary routes to Ah receptor activation. Drug Metab Dispos. 2015;43(10):1522-35. https://doi.org/10.1124/dmd.115.064246.

145. Valerio F, Lavermicocca P, Pascale M, Visconti A. Production of phenyllactic acid by lactic acid bacteria: an approach to the selection of strains contributing to food quality and preservation. FEMS Microbiol Lett. 2004; 233(2):289-95. https://doi.org/10.1111/j.1574-6968.2004.tb09494.x.

146. Jung $\mathrm{S}$, Hwang $\mathrm{H}$, Lee $\mathrm{JH}$. Effect of lactic acid bacteria on phenyllactic acid production in kimchi. Food Control. 2019;106:106701. https://doi.org/10.101 6/j.foodcont.2019.06.027.

147. Van der Meulen R, Scheirlinck I, Van Schoor A, Huys G, Vancanneyt M, Vandamme $P$, et al. Population dynamics and metabolite target analysis of lactic acid bacteria during laboratory fermentations of wheat and spelt sourdoughs. Appl Environ Microbiol. 2007;73(15):4741-50. https://doi.org/1 0.1128/AEM.00315-07.

148. Ryan LA, Dal Bello F, Czerny M, Koehler P, Arendt EK. Quantification of phenyllactic acid in wheat sourdough using high resolution gas chromatography-mass spectrometry. J Agric Food Chem. 2009;57(3):1060-4. https://doi.org/10.1021/jf802578e.

149. McSweeney PLH, Ottogalli G, Fox PF. Chapter 31 Diversity and classification of cheese varieties: an overview. In: McSweeney PLH, Fox PF, Cotter PD, Everett DW, editors. Cheese: chemistry, physics and microbiology. 4th ed. Amsterdam: Elsevier; 2017. p. 781-808. https://doi.org/10.1016/B978-0-12-41 7012-4.00031-4.

150. Kok CR, Hutkins R. Yogurt and other fermented foods as sources of healthpromoting bacteria. Nutr Rev. 2018;76(Suppl 1):4-15. https://doi.org/10.1 093/nutrit/nuy056

151. Rezac $S$, Kok CR, Heermann M, Hutkins R. Fermented foods as a dietary source of live organisms. Front Microbiol. 2018;9:1785. https://doi.org/10.33 89/fmicb.2018.01785.

152. Pasolli E, De Filippis F, Mauriello IE, Cumbo F, Walsh AM, Leech J, et al. Large-scale genome-wide analysis links lactic acid bacteria from food with the gut microbiome. Nat Commun. 2020;11(1):2610. https://doi.org/10.1038/ s41467-020-16438-8.

153. Tamang JP, Watanabe K, Holzapfel WH. Review: Diversity of microorganisms in global fermented foods and beverages. Front Microbiol. 2016;7:377.

154. Taylor BC, Lejzerowicz F, Poirel M, Shaffer JP, Jiang L, Aksenov A, et al. Consumption of fermented foods is associated with systematic differences in the gut microbiome and metabolome. mSystems. 2020;5(2):e00901-19. https://doi.org/10.1128/mSystems.00901-19.

155. Johnson AJ, Vangay P, Al-Ghalith GA, Hillmann BM, Ward TL, Shields-Cutler $\mathrm{RR}$, et al. Daily sampling reveals personalized diet-microbiome associations in humans. Cell Host Microbe. 2019;25(6):789-802.e5.

\section{Publisher's Note}

Springer Nature remains neutral with regard to jurisdictional claims in published maps and institutional affiliations. 